\title{
Géolinguistique
}

21 | 2021

Varia

\section{Un corpus perceptuel numérique d'anglais dublinois contemporain : enjeux, méthodes et constitution en période de Covid-19}

How to Build a Digital Perceptual Corpus of Contemporary Dublin English during the Covid-19 Pandemic: Stakes and Methods

\section{Christophe Coupé}

\section{OpenEdition}

Journals

Édition électronique

URL : https://journals.openedition.org/geolinguistique/5894

DOI : 10.4000/geolinguistique.5894

ISSN : 2650-8176

\section{Éditeur}

UGA Éditions/Université Grenoble Alpes

\section{Édition imprimée}

ISBN : 978-2-37747-303-8

ISSN : 0761-9081

\section{Référence électronique}

Christophe Coupé, « Un corpus perceptuel numérique d'anglais dublinois contemporain : enjeux méthodes et constitution en période de Covid-19», Géolinguistique [En ligne], 21 | 2021, mis en ligne le 06 décembre 2021, consulté le 19 décembre 2021. URL : http://journals.openedition.org/ geolinguistique/5894; DOI : https://doi.org/10.4000/geolinguistique.5894

Ce document a été généré automatiquement le 19 décembre 2021.

Géolinguistique 


\section{Un corpus perceptuel numérique d'anglais dublinois contemporain : enjeux, méthodes et constitution en période de Covid-19}

How to Build a Digital Perceptual Corpus of Contemporary Dublin English during the Covid-19 Pandemic: Stakes and Methods

\section{Christophe Coupé}

\section{Introduction}

La variation linguistique à l'œuvre dans la ville de Dublin n'est plus à établir (Brulard \& Navarro, 2015 ; Hickey, 2005b ; Moreno, 2010 ; Wells, 1982). La rupture linguistique entre les accents stéréotypiques du sud et du nord de Dublin a longtemps été symbolisée par la Liffey, fleuve traversant la ville, mais les récentes études (Hickey, 2005a ; Lonergan, 2013) ont démontré la coexistence d'accents dépassant la simple division nord/sud incarnée par ce fleuve. Partant de ce constat, une première question se pose : comment rendre compte de la diversité de ces accents? Afin de tenter de répondre à cette question, nous avons opté pour la création d'un corpus numérique d'anglais dublinois en dialectologie perceptuelle, dans le but d'explorer la piste de la perception dans une optique variationniste. L'impossibilité d'effectuer une enquête perceptuelle de terrain en raison de la pandémie de Covid-19 nous a poussé à changer de paradigme et à repenser la notion même d'enquête perceptuelle en lien avec le numérique. De fait, la création d'un corpus numérique d'anglais dublinois contemporain en dialectologie perceptuelle soulève, de par sa nature même, d'autres questions: quels outils et méthodes employer afin de créer et traiter un corpus perceptuel numérique? quels sont les contraintes et les avantages de la création d'un corpus numérique dans le cadre d'une telle étude? 
2 Dans la première partie, nous exposons brièvement notre cadre théorique, à savoir la perceptual dialectology et la linguistique de corpus, ainsi que les choix terminologiques effectués. La seconde partie, qui constitue le cœur de cet article, est consacrée à l'enquête perceptuelle numérique sur l'anglais dublinois contemporain menée en 2020. Nous y présentons la méthode de conception et de diffusion du questionnaire ainsi que les outils et méthodes de traitement des données. Nous y faisons également part d'une réflexion personnelle sur les avantages et inconvénients de ce type d'enquêtes au format numérique. Dans la troisième et dernière partie, nous présentons quelques résultats et pistes de réflexion. L'objectif ici n'est pas de présenter un ensemble de résultats, ce qui dépasse le cadre de cet article, mais plutôt d'exposer une réflexion méthodologique quant à la conception d'une enquête numérique en perceptual dialectology. De par le format peu classique de cette enquête perceptuelle numérique, notre travail est exploratoire et se veut être un lieu de réflexion qui, nous l'espérons, permettra à d'autres chercheuses et chercheurs d'approfondir la question du numérique et son apport dans les études en perceptual dialectogy (ou autres).

\section{Perceptual dialectology et corpus : considérations théoriques et épistémologiques}

\subsection{La perceptual dialectology : définition}

3 Les considérations sociolinguistiques et géolinguistiques, et l'intérêt pour le locuteur et ses représentations de la variation furent le point de départ de la réflexion menée en perceptual dialectology:

Après une époque où la recherche en géolinguistique se concentrait sur la description de la variation régionale, le champ s'est élargi vers une approche qui met le locuteur lui-même et sa vision des frontières dialectales (et de la variation en général, qu'elle soit sociale ou régionale) au centre des préoccupations. (Falkert, $2012: 124)$

4 La perceptual dialectology se démarque de la dialectologie traditionnelle par le point de vue qu'elle adopte (Falkert, 2012). Il s'agit non pas ici de mettre au centre de la réflexion la pensée scientifique, mais plutôt de recentrer la pensée du "non-linguiste " (Paveau, 2008b : 137) au cœur des préoccupations :

Contrairement à la dialectologie traditionnelle qui étudie la distribution des formes dialectales dans l'espace, la dialectologie perceptuelle se focalise sur la réalité perceptuelle de formes dialectales. À cet égard, elle s'intéresse à la personne même de l'informateur et non pas seulement aux données produites par celui-ci. (Falkert, $2012: 123)$

5 La perceptual dialectology est une branche de la Folk Linguistics ${ }^{1}$ ou, pour reprendre les termes de Marie-Anne Paveau (2008b : 137), de la « Folk Linguistique » et a pour objet d'étude les non-linguistes et leur perception de la variation linguistique (Cramer, 2016 :9). Elle propose une mise en perspective des variétés observées ainsi qu'une définition de leurs caractéristiques définitoires à l'aune de la perception que les locuteurs ont de ces variétés observées. La perceptual dialectology s'intéresse aux représentations mentales que les locuteurs se font des variétés observées, qu'Inoue (1996: 161) appelle dialect images et qu'il définit comme des représentations mentales géolinguistiques, ou mental maps (Inoue, 1996: 162). De par la nature subjective de ces représentations mentales, les dialect images relèvent d'un empirisme 
linguistique et géographique sous-jacent, car l'on doit avoir été confronté à une variété afin d'en avoir conscience et pouvoir se la représenter mentalement. La perceptual dialectology fait $\mathrm{du}$ non-linguiste un linguiste potentiel et explore ses évaluations possibles à propos d'une variété donnée ainsi que ses attitudes vis-à-vis de cette variété. Par nature, la perceptual dialectology est une discipline plurielle, à la croisée de la dialectologie et de la sociolinguistique.

\subsection{Perceptual dialectology : remarques et implications terminologiques}

\subsubsection{La distinction dialectology / « dialectologie »}

6 Selon Trudgill et Chambers (1998:3), la dialectologie, au sens anglais, s'intéresse à l'étude des dialects. Nous prenons soin d'utiliser ici les italiques en ce que dialect et « dialecte » ne recoupent pas les mêmes domaines épistémologiques comme le souligne Falker :

Le calque dialectologie perceptuelle (ou perceptive) pose problème dans la mesure où les (sous-) disciplines linguistiques dialectologie en français et dialectology en anglais ne recouvrent pas tout à fait le même domaine de recherche. On observe que le terme anglais dialectology a une portée plus générale, désignant ainsi le champ d'études qui englobe toute recherche sur la variation linguistique. (2012: 108-109)

7 En effet, dialect (et donc dialectology) fait référence à la variation diatopique et s'intéresse aux variétés dans un sens plus large. C'est avec l'acception du terme anglais à l'esprit que nous utiliserons dorénavant le terme «dialectologie » en français pour référer non pas à l'étude des dialectes, mais à l'étude des variétés. Hickey (2013:331) définit "variété » (variety) comme toute forme langagière que l'on peut distinguer d'une autre, et ce, sans aucune connotation, contrairement aux dialects qui sont emprunts d'une connotation négative ${ }^{2}$; en anglais les dialectes sont inclus dans les dialects. Ainsi, il convient d'utiliser les termes dialect et « dialecte " à bon escient, car, en français, « dialecte » réfère à la variation dialectale et donc aux dialectes qui sont un type de variétés parmi d'autres (sociolectes, ethnolectes, technolectes, idiolectes, etc.). Les « dialectes » sont l'objet d'étude de la « dialectologie » qui s'intéresse à ces parlers locaux géographiquement délimités (Dalbera, 2013: 173-174). Ce ne sont pas eux qui nous intéressent ici, mais bien les variétés de l'anglais dublinois contemporain au sens large. À l'aune de ces informations, cette étude prend le parti d'utiliser « dialectologie » dans l'acception large du terme anglais dialectology et s'intéresse, de fait, à la variation diatopique dans son ensemble. Qu'en est-il du terme perceptual ?

\subsection{Dialectologie « perceptuelle » ou « perceptive »?}

On retrouve dans la littérature scientifique deux termes référant à la perceptual dialectology en français : dialectologie " perceptuelle » et dialectologie " perceptive ». Il ne semble pas exister de consensus sur l'utilisation de ces termes pour traduire l'adjectif perceptual. Pourtant, la coexistence de deux termes en français pointe nécessairement vers une différence terminologique implicite en ce que deux termes ne peuvent renvoyer à la même réalité linguistique sans aucune nuance - aussi ténue 
soit-elle. De plus, il ne semble y avoir, dans la littérature, de réelle discussion sur le statut épistémologique de la dialectologie perceptuelle et de la dialectologie perceptive.

Le terme «dialectologie perceptuelle» a été préféré à celui de «dialectologie perceptive" dans le cadre de notre enquête en ce qu'il existe, d'après nous, une distinction d'ordre épistémologique entre ces deux termes qui, s'ils ne sont pas totalement opposés, ne sont pas à confondre. Est dit « perceptif» (ou « perceptive »), ce qui relève de l'ordre de la perception et de l'évaluation de stimuli oraux. En phonétique descriptive et en phonologie, notamment dans les enquêtes de terrain, l'oreille est le premier instrument d'investigation utilisé. Il est ainsi important de bien connaître le fonctionnement $\mathrm{du}$ système perceptif puisque les propriétés de ce système conditionnent la façon dont nous appréhendons les phénomènes phonétiques et phonologiques (Nguyen, $2007: 1$ ). Ngyuen associe « l'auditif », « l'oreille », au « système perceptif» qui renvoie au système auditif. Le perceptif nécessite donc une appréhension de phénomènes phonétiques et phonologiques - pour reprendre les mots de Nguyen - via l'écoute de stimuli oraux ${ }^{3}$. Virole (2006: 115-118) parle de "processus auditivo-perceptifs » et de "mécanismes perceptifs auditifs » et associe, sans équivoque, le perceptif à l'auditif. Les travaux de Virole et Nguyen semblent tous deux s'orienter vers une même utilisation de l'adjectif «perceptif». Nous verrons en 3.3 que le perceptif est restreint à un type de tâches en particulier dans les enquêtes en perceptual dialectology.

10 A contrario, est dit "perceptuel » (ou "perceptuelle ») ce qui relève de l'étude des représentations et attitudes des locuteurs vis-à-vis d'une variété donnée. Le perceptuel n'implique pas, contrairement au perceptif, de soumettre des stimuli oraux à l'appréciation des locuteurs. Le perceptuel s'intéresse davantage à l'imaginaire perceptuel $^{4}$ des locuteurs, aux attitudes, aux jugements à l'encontre d'une variété donnée. À l'aune de la distinction que nous venons d'établir, il semblerait y avoir une continuité dans les études francophones entre la «dialectologie perceptuelle " et "dialectologie perceptive » qui ne sont pas à opposer, mais bien à considérer comme étant la continuité d'une même approche globale, celle de l'étude de la perception des locuteurs. À défaut de trouver un terme regroupant conjointement les notions de perceptif et de perceptuel, le recours au terme perceptual reste, nous semble-t-il, plus judicieux si l'on souhaite parler de la perceptual dialectology. L'étude de la perception peut se faire tantôt par le prisme du perceptuel, tantôt par le prisme du perceptif, ou bien par une combinaison des deux. Le critère permettant de situer une enquête en dialectologie perceptuelle ou en dialectologie perceptive est celui du type de tâches effectuées ${ }^{5}$.

\subsection{Les différentes tâches dans les enquêtes en dialectologie perceptuelle et perceptive}

11 Une des tâches utilisées en dialectologie perceptuelle, sans doute la plus récurrente, est le dessin sur fond de carte ou draw-a-map task. Elle nécessite pour les enquêtés de délimiter sur une carte des zones où, d'après eux, sont parlées des variétés communes ou différentes (Preston, 1999 : xxxiv). Il est parfois demandé aux enquêtés de nommer ces zones et de fournir des commentaires à propos des variétés qui y sont parlées. Le degré de différence est une autre tâche utilisée et consiste à définir à quel point, pour un enquêté, la variété désignée est différente de la sienne en matière d'intelligibilité. 
Une autre tâche à laquelle on a souvent recours est celle de l'évaluation d'une variété donnée en matière de pleasantness et correctness ${ }^{6}$ par l'attribution d'une note. La dernière tâche que nous présentons ici est celle de l'identification de dialectes à travers l'écoute d'enregistrements. On présente aux enquêtés sans information préalable sur les variétés qu'ils vont écouter des enregistrements qu'on soumet à leur évaluation. À l'issue de l'écoute de ces enregistrements, les enquêtés doivent associer les variétés écoutées à une zone (ou plusieurs) sur une carte. À la lumière de la distinction "perceptuelle» / "perceptive » effectuée en 2.3 , nous souhaitons indiquer ici qu'il s'agit d'une tâche relevant de la dialectologie perceptive, car elle est essentiellement fondée sur l'écoute de stimuli oraux.

Nous avons sélectionné pour notre enquête le dessin sur fond de carte ainsi que l'évaluation des variétés repérées selon les critères pleasantness et correctness. Cette étude se posant comme une enquête préliminaire visant à repérer un ensemble de variétés parlées dans la ville de Dublin, il nous semblait contre-productif de soumettre des enregistrements aux enquêtés, car cela aurait sous-entendu que nous avions déjà connaissance des variétés parlées à Dublin. Or, notre approche est tout autre, et repérer des zones d'intérêt nous semblait être indispensable avant de pouvoir enregistrer des locuteurs sur le terrain.

\subsection{La notion de « corpus » perceptuel}

13 Peut-on parler d'un "corpus» perceptuel dans le cadre de notre enquête? Cette question se pose d'autant plus compte tenu de la taille limitée des données récoltées. Elle est également au centre de la réflexion proposée par Chatellier et Viollain (2018) qui s'interrogent sur le statut d'un ensemble de données restreint par rapport aux grands corpus que sont, par exemple, le BNC ou le COCA :

[...] défendre l'utilisation et la validité des petits corpus spécifiquement pourrait donc ressembler à une mission impossible tant les grands corpus semblent bénéficier, de façon presque automatique, d'une supériorité scientifique, et même d'une certaine forme d'indulgence de la part des sceptiques, car ils sont censés être plus représentatifs de la langue ou de la variété d'une langue étudiée, et donc fournir des informations plus solides aux chercheurs, ne serait-ce que d'un point de vue statistique. (2018:1-2)

Les interrogations soulevées par ces auteurs concernent les petits corpus phonologiques, mais elles peuvent se rapporter à tous les "petits» corpus indépendamment $\mathrm{du}$ format des données. En linguistique de corpus, on appelle « corpus » tout ensemble de textes ${ }^{7}$ stockés dans une base de données électronique et sélectionnés dans le but d'atteindre la représentativité du phénomène linguistique observé (Baker et al., 2012: 48-49). L'on a souvent tendance à corréler taille et représentativité. À juste titre, Chatellier et Viollain (2018:5-6) soulignent que ce que l'on appelle petit ou grand corpus n'est qu'affaire de relativité et de point de vue, d'autant que la représentativité linguistique, de par le caractère évolutif de la langue, ne reste qu'un idéal. Ce constat soulevé par ces mêmes auteurs permet, pour reprendre le terme, de " dédramatiser » la notion de taille des corpus. Ils proposent de repenser la notion de représentativité non pas en matière de taille, mais, d'après Gut et Voormann (2014: 22) en matière de contrôle et de " coût humain et financier ». Un petit corpus permet l'utilisation d'un protocole de recherche plus détaillé en raison du nombre moins important de données collectées alors que le protocole adopté pour un 
grand corpus doit être facilement reproductible et permettre de collecter un grand nombre de données facilement comparables. Ce que l'on gagne en nombre dans les grands corpus se perd en précision, alors qu'un petit corpus pourra bénéficier d'un traitement plus approfondi en raison d'un protocole plus détaillé (Chatellier \& Viollain, $2018: 8$ ). Afin de résumer cette approche, nous proposons le schéma suivant qui représente ce que nous appellerons « échelle de représentativité d'un corpus » :

Figure 1. - Échelle de représentativité d'un corpus en linguistique de corpus, d'après Chatellier et Viollain (2018).

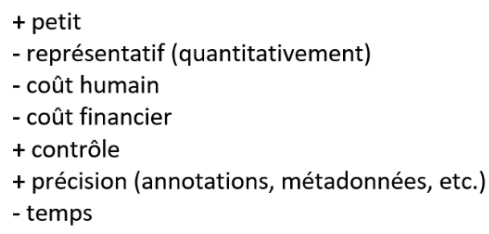

Nous souscrivons pleinement à la vision de Chatellier et Viollain et souhaitons ajouter que notre corpus perceptuel ne vise pas une représentativité quantitative, mais propose des données perceptuelles aussi représentatives que possible en fonction du coût humain et financier de notre corpus et en fonction des objectifs de notre étude. À l'instar de Chatellier et Viollain (2018:8), il nous semble que tout l'enjeu de la construction d'un corpus réside dans la finalité de l'étude menée. Nous appellerons donc «corpus perceptuel» ce corpus que nous avons entièrement constitué seul et supervisé dans son ensemble.

\section{Création d'un corpus perceptuel numérique d'anglais dublinois: choix et méthodologie}

\subsection{Pourquoi une enquête perceptuelle au format numérique?}

Comme il a été indiqué en première partie, les enquêtes perceptuelles revêtent un format bien plus traditionnel que celui que nous avons adopté. Il importe donc d'expliciter les raisons qui nous ont poussé à opter pour le format numérique. Notre objectif premier était de récolter un échantillon de données perceptuelles variées auprès d'une cinquantaine d'enquêtés afin d'obtenir un nombre de données comparables à celles collectées par Lonergan (2013) dans le cadre de sa thèse. Toutefois, l'anxiété croissante quant au virus Covid-19 avait déjà gagné l'Europe à la fin du mois de février 2020 et un départ ne put être envisagé pour des raisons évidentes. La pandémie nous a poussé à repenser notre enquête et à trouver un moyen de contourner l'obstacle majeur (im)posé par le virus. C'est alors que nous nous sommes tournés vers le numérique afin de tenter de récolter des données perceptuelles. Comme nous le verrons en 3.3, les tâches présentées en 2.4 ne se prêtent pas, pour la plupart, entièrement au format numérique et il nous a donc fallu repenser certaines de ces tâches. Si l'été 2020 aurait pu constituer une période propice à la collecte de données perceptuelles de terrain, le climat de méfiance généralisée dû au Covid-19 aurait représenté un frein non négligeable au bon déroulement de l'enquête. 
17 Cette enquête perceptuelle trouve toute sa place au sein d'une étude sociophonologique de l'anglais dublinois contemporain de plus grande envergure et lui sert ainsi de point de départ. Nous souhaitons faire de cette étude perceptuelle un travail préliminaire permettant de mieux appréhender la réalité sociolinguistique dublinoise et de comparer les données perceptuelles recueillies aux résultats d'une future enquête socio-phonologique de terrain. Dans notre cas, l'enquête perceptuelle n'est pas une fin en soi, mais constitue le point de départ d'une réflexion méthodologique, épistémologique et sociolinguistique sur le statut de la variation et sur les moyens dont on dispose afin de rendre compte de la variation diatopique. Après avoir abordé la structure et la mise en place de l'enquête perceptuelle numérique, il importe d'aborder la question des avantages du format numérique, mais également les inconvénients rencontrés avant, pendant et après l'enquête.

\subsection{Déroulement et structure de l'enquête numérique}

\subsubsection{Diffusion du questionnaire}

18 Le questionnaire a été mis en ligne de février 2020 jusqu'à fin août 2020 afin de récolter suffisamment de données exploitables. Le questionnaire était adressé exclusivement aux personnes vivant à Dublin et son aire urbaine (de nombreuses personnes travaillent en ville et habitent en périphérie). Le questionnaire a tout d'abord été distribué auprès de nos contacts personnels qui se sont chargés de nous faire un retour afin que nous ajustions le questionnaire. Le questionnaire a été diffusé sur le réseau social Facebook, sur le forum Boards.ie sur lequel de nombreux Irlandais sont inscrits, ainsi que sur la plateforme Reddit et plus particulièrement dans le groupe « $r$ /Ireland » qui comptabilise près de 350000 Irlandais inscrits. Soulignons que c'est grâce à la plateforme Reddit, qui bénéficie d'une visibilité accrue sur internet, que nous avons pu obtenir la très grande majorité de nos résultats.

\subsubsection{Organisation du questionnaire}

19 Le questionnaire est divisé en trois parties. Une introduction précède le questionnaire et informe les enquêtés des raisons et objectifs de cette enquête. La première partie est consacrée à une série de questions visant à obtenir des renseignements sur les enquêtés. Ces questions fournissent des métadonnées afin de renseigner le corpus d'étude et de comparer les données de chaque locuteur entre elles suivant des critères précis (âge, genre, niveau d'études, etc.) :
1. Gender
2. Age
3. Where in Dublin do you live? Indicate suburb; do not give precise address
4. Have you always lived in Dublin?
4a. When did you move to Dublin?
4b. Where did you live before moving to Dublin? ${ }^{8}$
5. Where is your mother originally from?
6. Where is your father originally from?
7. What is your occupation? (If any)
8. What is your highest educational achievement? (If any) ${ }^{9}$ 
Ces questions ont été reprises, pour la plupart, de l'enquête de Lonergan (2013), et ce à des fins de comparabilités des données. De plus, il nous semblait pertinent de mettre à l'épreuve la méthodologie de Lonergan et d'adapter cette dernière. La création d'un protocole d'enquête aurait constitué une trop lourde tâche, en plus du passage au format numérique. Notre parti pris a donc été de nous inspirer des travaux d'autres chercheurs afin de tenter, à notre tour, de développer une méthodologie propre aux enquêtes perceptuelles numériques.

Figure 2. - Vue d'ensemble de Dublin sans annotation.

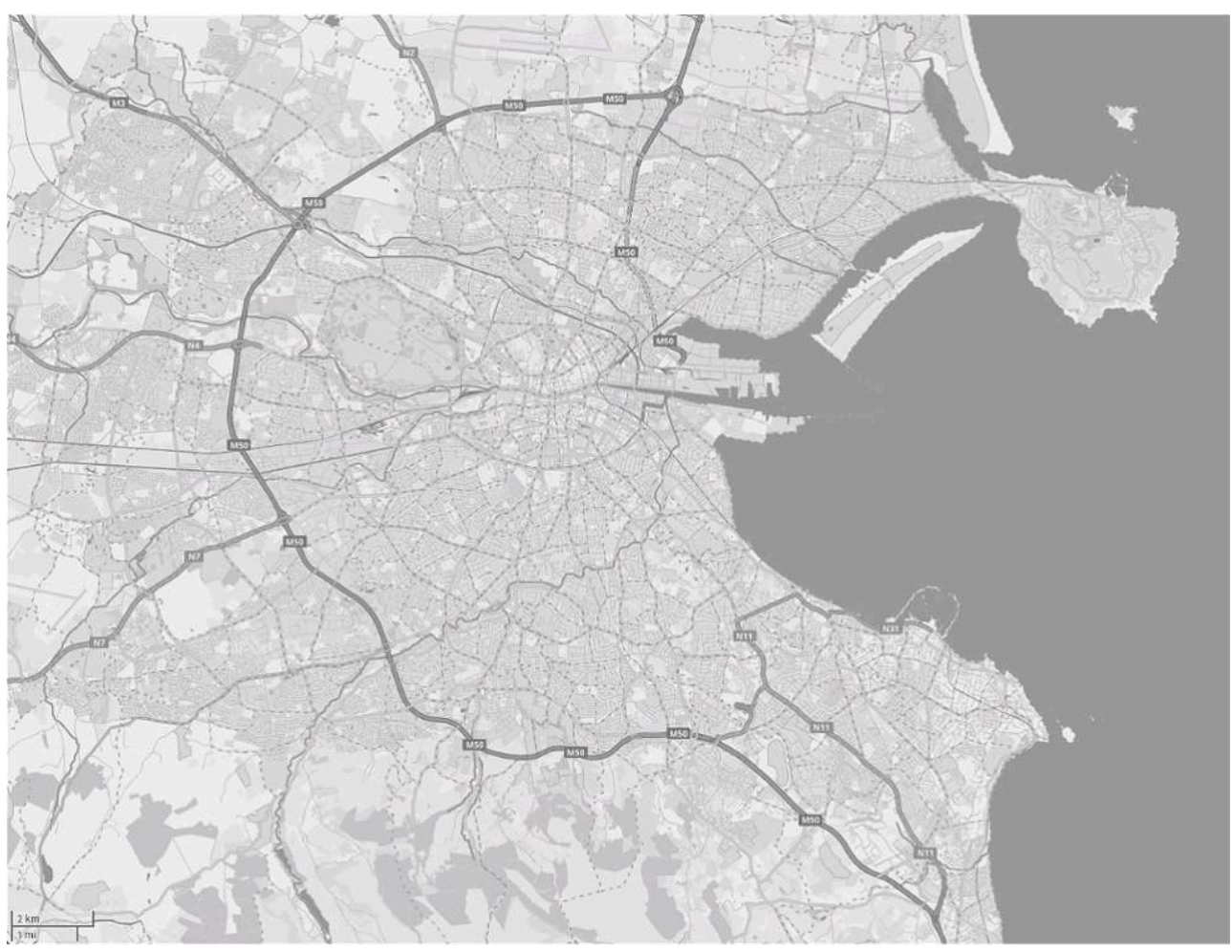

Source : <https://umap.openstreetmap.fr/fr/>

21 La seconde partie du questionnaire constitue le cœur de l'enquête. La tâche principale de ce questionnaire consistait à créer des ensembles de zones où, selon les enquêtés, les personnes parlent de la « même façon ». Deux cartes étaient proposées à l'attention des enquêtés. La carte comportant les délimitations des quartiers de Dublin (fig. 4) a été obtenue par superposition d'une carte vierge (fig. 2) et d'un schéma représentant la répartition géographique des quartiers de Dublin (fig. 3). Nous avons ensuite sousdivisé les quartiers afin d'obtenir des zones plus petites permettant aux enquêtés d'être plus précis dans leurs repérages. Si les sous-divisions semblent arbitraires, elles suivent autant que possible certains grands axes et isolent certains lieux tels que le campus universitaire de Blackrock ou la zone portuaire de Dún Laoghaire. Dans le cas de très grands quartiers tels que le quartier 15 ou 24, la division a été effectuée de manière concentrique en prenant le centre-ville comme point de repère. Un total de 40 zones sont présentes sur la carte. De plus, afin de ne pas surcharger davantage la carte, nous avons pris le parti de ne pas sous-diviser davantage les grands quartiers situés en périphérie et avons préféré nous concentrer sur ceux situés à l'intérieur de la M50 
(périphérique autoroutier), car ce sont ceux qui présentent la plus forte concentration de population ${ }^{10}$.

Figure 3. - Les différents quartiers de Dublin.

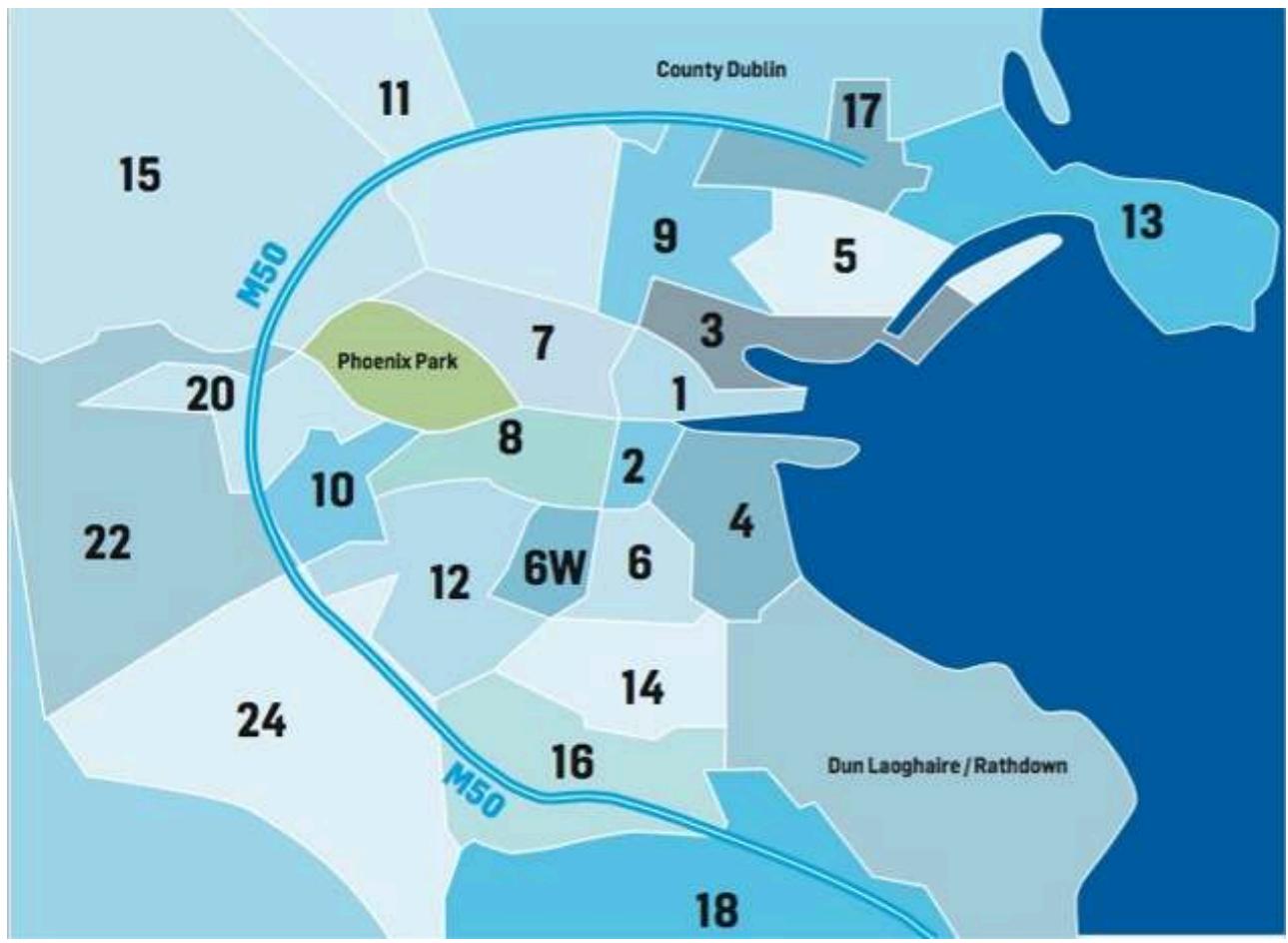

Source : <https://www.ifsc.ie/article.aspx?idnews=436340>.

Figure 4. - Délimitation et sous-division des quartiers de Dublin.

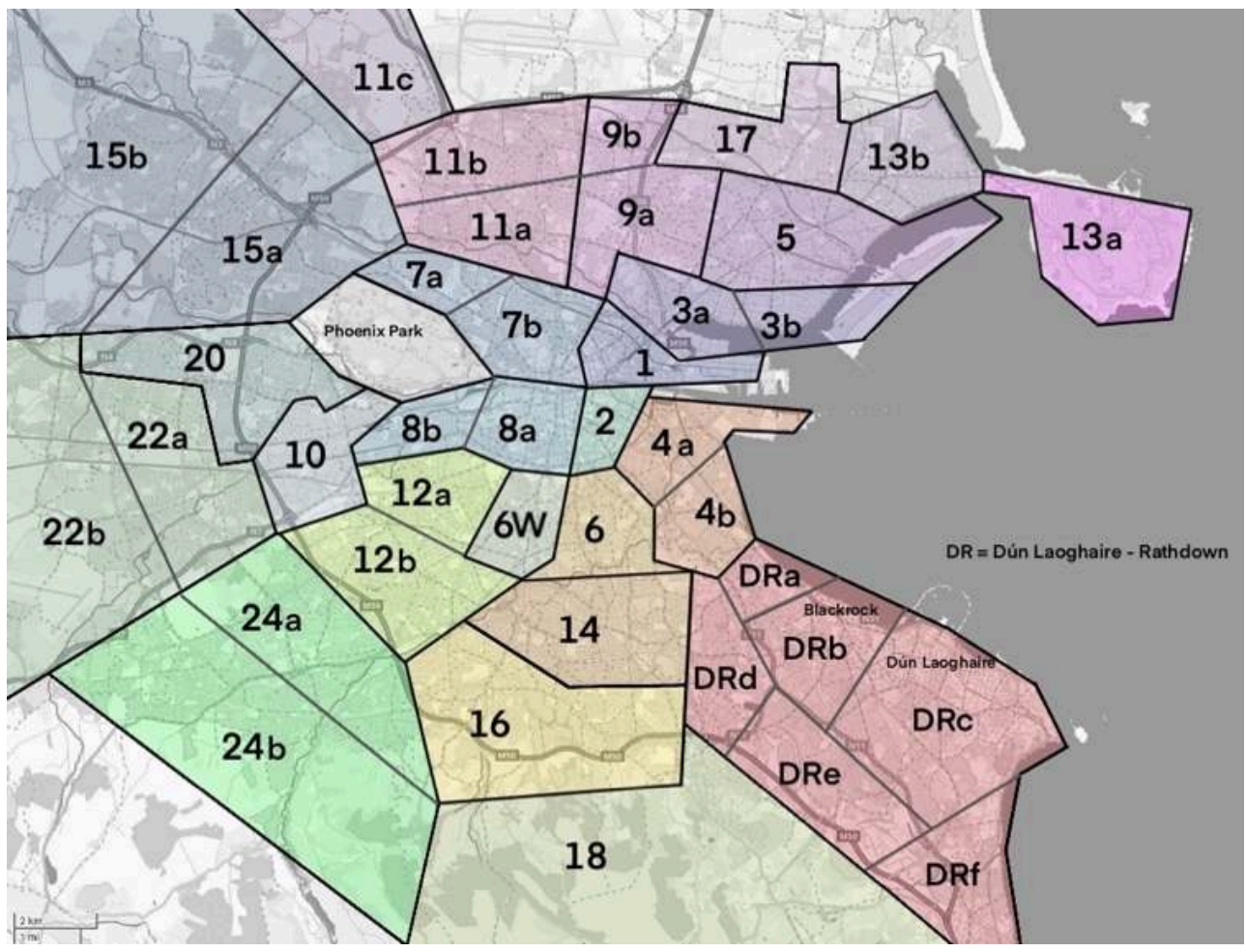



d'une carte fournie, des ensembles de zones où, d'après eux, les personnes vivant dans ces différentes zones parlent des variétés semblables. La question posée était volontairement vague afin de ne pas influencer les locuteurs :

Here is a map of Dublin city to help you in case you need to know the names of the neighbourhoods: Can you make groups of areas where you think people speak the same using the map below? You can make as many groups as you wish.

To do so, you need to identify the groups as shown in the example below:

Group $A=1243 a 8$ Group $B=18720511 a 11 b$ Group $C=1612 a$ 12b 24a Group D = DRa DRb $1022 a$ Group $E=. .$.

Use as many numbers as you want in order to identify groups of areas where people speak the same (you don't need to use all the numbers). Please make sure to use spaces ${ }^{12}$ between the numbers ${ }^{13}$.

Nous aurions pu mettre l'accent sur les différences plutôt que sur les similarités; cependant, Weijnen émet de fortes réserves quant à l'approche adoptée par Grooaters qui interroge les locuteurs sur les différences entre les variétés :

He asked his informants whether they perceived stronger or weaker differences between their dialect and the neighboring dialects, which he indicated one by one [...].

However, as I have already stated, the formulation of his question was incorrect. One cannot ask ordinary people to say where faraway dialect borders exist; if that is done, errors are inevitable. And because differences within one's immediate surroundings always do exist, the likelihood is very high that informants will answer the question of whether or not they perceive differences between their dialect and that of the neighboring village with an affirmative answer. This was the reason I, back in 1944, judged the kind of question formulation Grootaers used as misguided. Instead, one should ask informants where similar dialects are spoken ${ }^{14}$. (1999: 131-132)

D'après Weijnen, il semble plus pertinent d'insister sur les similarités, sur ce qui rapproche deux variétés parlées dans deux zones distinctes. L'on pourrait ajouter qu'interroger des locuteurs sur les similarités entre deux zones (ou deux groupes de zones dans le cas de notre enquête) amène nécessairement à indiquer des différences, car comme l'indique Weijnen, un locuteur perçoit toujours une différence entre sa propre variété et une autre de son environnement immédiat. Par environnement immédiat, nous entendons l'environnement géographique et variationnel proche des locuteurs; cet environnement immédiat se retrouve nécessairement déterminé par l'empirisme linguistique des locuteurs qui doivent avoir été confrontés à une variété proche de leur lieu de vie.

De plus, il convient de souligner, pour des raisons purement pratiques, qu'il semble moins périlleux de grouper des zones selon la ressemblance des variétés qui y sont parlées plutôt que selon les différences, car cela nous conduirait potentiellement à établir un nombre de groupes de zones excessivement important et rendrait toute carte perceptuelle illisible. Nous avons ensuite demandé aux enquêtés d'attribuer aux variétés perçues une note allant de 1 à 5 en matière de pleasantness et correctness et de décrire ces variétés.

Le questionnaire s'achève sur plusieurs questions visant à informer les enquêtés de la durée de conservation des données et à recueillir leur consentement éclairé. À l'issue du questionnaire, nous avons laissé la possibilité aux enquêtés de nous laisser leur adresse mail afin que nous puissions les recontacter en vue d'une future enquête de terrain lorsque la situation sanitaire le permettra. 


\subsection{Avantages et inconvénients d'une enquête perceptuelle au format numérique} l'enquêteur pose directement les questions à l'enquêté et, de fait, aucune tâche de lecture de la part de l'enquêté n'est nécessaire (dans notre cas). Falkert souligne que «ces méthodes d'enquête ne s'adaptent pas facilement à tous les publics que le chercheur est susceptible de rencontrer »(2012: 124). Toutefois, nous avons pleinement conscience que notre questionnaire n'est pas adapté aux personnes en situation d'illettrisme, de par son format et sa méthode de diffusion, et nous prive ainsi de précieux résultats et analyses. Si ces personnes représentent environ $1 \%$ de la population totale en Irlande, nous avions néanmoins pour projet de créer une enquête qui soit la moins exclusive possible.

Une autre difficulté s'est imposée lors de la diffusion du questionnaire : le public visé. Ce questionnaire avait pour ambition première d'être diffusé auprès de personnes de tout âge. Cependant, il convient de noter qu'il est très difficile, voire impossible que ce questionnaire numérique arrive entre les mains de personnes âgées (70 ans et plus) qui, d'après notre expérience, ne font que très peu, voire pas du tout, usage des outils numériques. Il s'agit ici d'un problème lié au numérique auquel nous n'avons pas trouvé de solution. La méthode de diffusion du questionnaire (voir 3.2.1) exclut malheureusement les personnes âgées et cette difficulté se pose moins lorsque l'enquête est effectuée sur le terrain. S'il est souvent difficile d'interviewer des personnes âgées, car certaines d'entre elles vivent dans des maisons de retraite à partir d'un certain âge et qu'il faut obtenir une autorisation auprès de ces dernières 
(Lonergan, $2013: 62$ ), cela reste tout de même une entreprise envisageable et réalisable sur le terrain.

31 Notons cependant que le format numérique de ce questionnaire comporte des avantages non négligeables. Tout d'abord, le numérique favorise la récolte semiautomatique de données une fois le questionnaire mis en ligne. Ainsi, la tâche principale de l'enquêteur s'en retrouve raccourcie et consiste essentiellement en l'élaboration du questionnaire, sa diffusion et le téléchargement des données stockées en ligne. La possibilité de collecter semi-automatiquement des données fait la force de ce questionnaire numérique. Dans sa thèse, Lonergan (2013) a adapté la méthode de numérisation et superposition de cartes papier mise au point par Bounds (2010) dans le cadre d'une étude perceptuelle sur les variétés polonaises. Si cette méthode permet d'obtenir des résultats depuis des cartes papier, elle semble toutefois difficilement exploitable dans le cadre de notre enquête, du fait de l'absence même de ces cartes papier ${ }^{15}$. Le format numérique permet de contourner cette tâche de numérisation et de conversion assez lourde qui demande une certaine expertise de l'outil informatique. La méthode à laquelle nous avons recouru est beaucoup plus accessible du fait du format de l'enquête et ne nécessite pas ou peu de compétences en informatique. La prise de distance physique imposée par le format numérique limite, dans une certaine mesure, les effets du paradoxe de l'observateur (Labov, 2006: 86) du fait de l'absence de l'enquêteur au cours de l'enquête. Au vu des réponses collectées auprès des enquêtés, et notamment au niveau des commentaires métalinguistiques fournis dans les questionnaires ${ }^{16}$, nous pouvons noter une certaine spontanéité qui semble bien moins contrainte par la présence de l'enquêteur. Nous pensons donc que, dans l'ensemble, l'intérêt et la pertinence scientifique des résultats collectés ne sont pas amoindris par le format adopté par l'enquête. Par ailleurs, cette distance physique s'est avérée salvatrice dans le cadre de notre enquête, car nous n'aurions pu collecter de données autrement en raison de la pandémie actuelle et des restrictions de déplacement entre les pays. Il importe à présent de revenir sur la méthode et les outils utilisés dans le cadre de cette enquête de manière la plus exhaustive possible afin de justifier la faisabilité et l'utilité d'une enquête perceptuelle au format numérique.

\subsection{Outils et traitement des données collectées}

\subsubsection{Création, extraction et organisation}

Le questionnaire a été créé à l'aide du logiciel en ligne LimeSurvey qui offre tout un éventail de paramétrages de questions (zones de texte, listes, etc.). Les fonctionnalités avancées de ce logiciel permettent aux utilisateurs, par exemple, de prévoir des scénarios de réponse (fig. 5). Ces scénarios donnent la possibilité de faire apparaître ou disparaître des questions qui dépendent (ou non) de la question précédente. Les scénarios allègent le nombre d'informations présentes à l'écran. Ainsi, l'enquêté est moins submergé d'informations non nécessaires en fonction des réponses fournies. La granularité des paramétrages constitue un atout non négligeable dans la création d'un questionnaire. Dans LimeSurvey, les données collectées peuvent être exportées en différents formats (.xml, PDF, Excel, Word, HTML). 
Figure 5. - Paramétrage de scénarios de questions dans LimeSurvey.

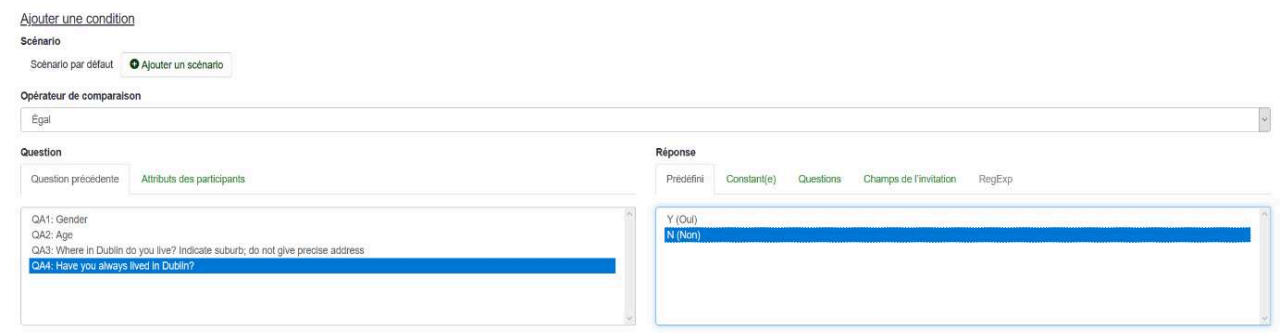

Outre les nombreuses possibilités de paramétrage offertes par LimeSurvey, un autre détail a attiré notre attention- : la sécurité des données collectées. Conformément au Règlement général à la protection des données (RGPD), la CNIL impose une sécurisation optimale des données personnelles collectées afin de ne pas mettre en danger les personnes interrogées et leur identité, mais également afin de ne pas se mettre en danger - juridiquement parlant - en tant que chercheur. Le logiciel LimeSurvey fourni par notre institution (université Jean Moulin Lyon 3) voit ses données stockées sur des serveurs sécurisés situés à Lyon. La proximité de ce centre de données ainsi que sa présence sur le sol européen constituent un gage de sécurité optimale. Les considérations éthiques liées à la collecte de données personnelles sont nombreuses et la sécurité des données représente un enjeu de taille dans toute enquête qui doit s'assurer de la bonne conservation de ces dernières. Une fois les données collectées à l'aide du logiciel en ligne LimeSurvey, nous avons procédé à l'exportation de ces dernières au format .xlsx pour les traiter dans Microsoft Excel. Un code a ensuite été attribué aux enquêtés (fig. 6) comme suit: id_âge_sexe ${ }^{17}$. Ainsi, par exemple, la personne désignée par le code 12_F_27 est la douzième personne à avoir répondu au questionnaire et il s'agit d'une femme âgée de 27 ans. Les données ont ensuite été classées en fonction du sexe dans deux tableurs différents.

Figure 6. - Aperçu des données collectées auprès des enquêtés (bleu = femme ; vert $=$ homme) dans l'interface Microsoft Excel.

\begin{tabular}{|c|c|c|c|c|c|c|c|c|c|c|}
\hline & A & B & c & D & E & $\mathbf{F}$ & G & H & 1 & \\
\hline 1 & Response 10 & Gender & Age & Where in Dublin doy & yithave you alv & o When did you move & "Where did you use to & What parts of Dublin! & there is your mother & When \\
\hline 2. & & 3 Female & & 24 Foxrock & Yes & & & South side & Sligo & Mayo \\
\hline 3 & & 12 Female & & 27 Suburb & Yes & & & North Co. Dublin, Sot & ¿Lucan, Dublin & Glasn \\
\hline 4 & & 17 Female & & 49 Ssillorgan & Yes & & & Dublin 8 \& Stillorgan & Cork & Wext \\
\hline 5 & & 39 Female & & 52 Sollorgan & Yes & & & Dunlaoghaire & Louth & Dublit \\
\hline 6 & & 48 Male & & 39 Clontar & No & Six years ago & In Naas, very close to & o Clontart, Eastwall & Dublin city & Dubli \\
\hline 7 & & 54 Female & & 28 Donnybrook & No & December 2016 & Greece & Rathmines, Crumlin, I & IGreece & Grees \\
\hline 8 & & 65 Male & & 36 Rathmines & No & January 2019 & Wicklow & Rathmines & Waterford & Wickl \\
\hline 9 & & 78 Female & & 24 Windy Arbour & Yes & & & Only Windy Arbour & Windy Arbour, Dublin & Cahir \\
\hline 10 & & 82 Female & & 31 Lucan & No & 201 & Spain & Ranelagh, Drumcond & Dundalk, reland & Porta \\
\hline 11 & & 96 Female & & 27 Dublin 8, Portobello & No & Septomber 2019 & Paris, France & Only Dublin 8 so far: & County Wicklow, Irela & Esses \\
\hline 12 & & 97 Male & & 27 Drumcondra & No & 200 & 1 Paris & Drumcondra & Dublin & Paris \\
\hline 13 & & 98 Female & & 25 Rathmines, Dublin 6 & No & in 2017 & France, in Creusot & Foxrock in Sandytord & France & Franc \\
\hline 14 & & 09 Female & & 56 Glasnevin Dublin 11 & No & 198 & 2 Sligo & Sandymount, ballsbri & Sligo & Sligo \\
\hline 15 & & 16 Male & & 24 Dun Laoghaire & No & I was bom and raise & d Montpellier & Dun Laoghaire & Dalkey & cork \\
\hline 16 & & 18 Male & & 23 Suburb & No & 4 years old & Suburbs & The south then the nc & cCameroon & Came \\
\hline 17 & & 20 Female & & 38 Dublin west & Yes & & & Dublin 6 Dublin 8 Dul & I Dublin & Dublii \\
\hline 18 & & 24 Female & & 23 Tallaght Dublin 24 & Yes & & & Tallaght & Perrystown Dublin 14 & 4 Tallas \\
\hline 19 & & 27 Male & & 55 Sandytord & Yes & & & Blackrock, Sandyford & Dublin & Dubli \\
\hline 20 & & 35 Female & & 57 North Strand & Yes & & & Raheny North Strand & Drumcondra & Glasn \\
\hline & & 51 Female & & 33 Dublin 15 & Yes & & & Dublin 15 and 7 & Dublin 7 & Dublii \\
\hline
\end{tabular}

34 Nous avons ensuite procédé au classement des données selon différents critères détaillés ci-dessous :

- Répartition hommes/femmes en deux tableurs distincts ;

- Répartition des enquêtés selon l'âge, le niveau d'études ainsi que le lieu de naissance (né(e) à Dublin, en Irlande ou à l'étranger) ; 
- Répartition hommes/femmes suivant la fréquence de repérage pour chacun des quartiers (fig. 7) ;

- Répartition des réponses suivant le lieu de naissance des enquêtés ;

- Classement des notes pleasantness et correctness selon le sexe ;

- Classement des auto-évaluations selon le sexe ;

- Classement des évaluations (commentaires métalinguistiques) sur chaque variété perçue selon le sexe et le lieu de résidence (district).

Si nous ne prétendons pas à l'exhaustivité en matière de classement des données, nous cherchions, avant tout, à les organiser suivant des critères précis, en lien avec les questions posées en première partie du questionnaire ${ }^{18}$, nous permettant de mieux appréhender le lien entre la variation et les représentations et attitudes des locuteurs interrogés. La figure 7 ci-dessous donne un aperçu de l'ampleur que représente l'organisation des données.

Figure 7. - Exemple d'organisation des résultats des enquêtés (hommes) selon le nombre de zones repérées pour chacun d'entre eux ( 1 = quartier désigné par l'enquêté dans le questionnaire ; grisé = quartier non désigné par l'enquêté).

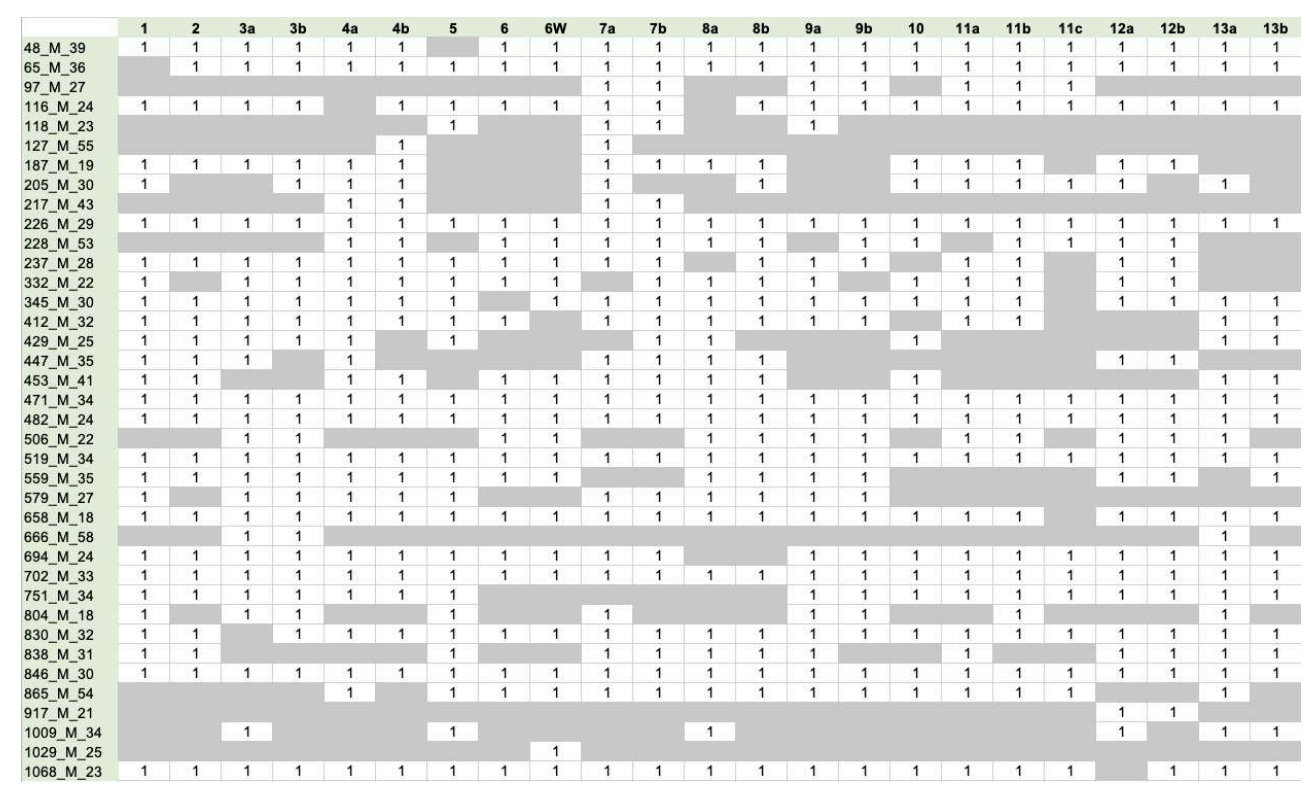

\subsubsection{Créer des cartes perceptuelles}

Dans un second temps, des cartes perceptuelles individuelles et groupées ont été créées afin d'obtenir une meilleure vue d'ensemble de la répartition des résultats sur le territoire observé. Pour ce faire, nous avons eu recours au logiciel Procreate ${ }^{19}$ (fig. 8). Il s'agit d'une application sur tablette destinée aux arts graphiques numériques. Nous avons détourné son usage premier afin de nous en servir d'outil de création de cartes. L'intérêt d'un tel logiciel réside dans la pluralité des fonctionnalités offertes; nous pensons notamment à la superposition de calques, à l'outil de sélection automatique et à l'outil de remplissage automatique. Procreate est un logiciel comparable à Adobe Photoshop arborant une interface intuitive et accessible aux plus débutants. 
Figure 8. - Capture d'écran de l'environnement de travail Procreate (v. 5.0.6).

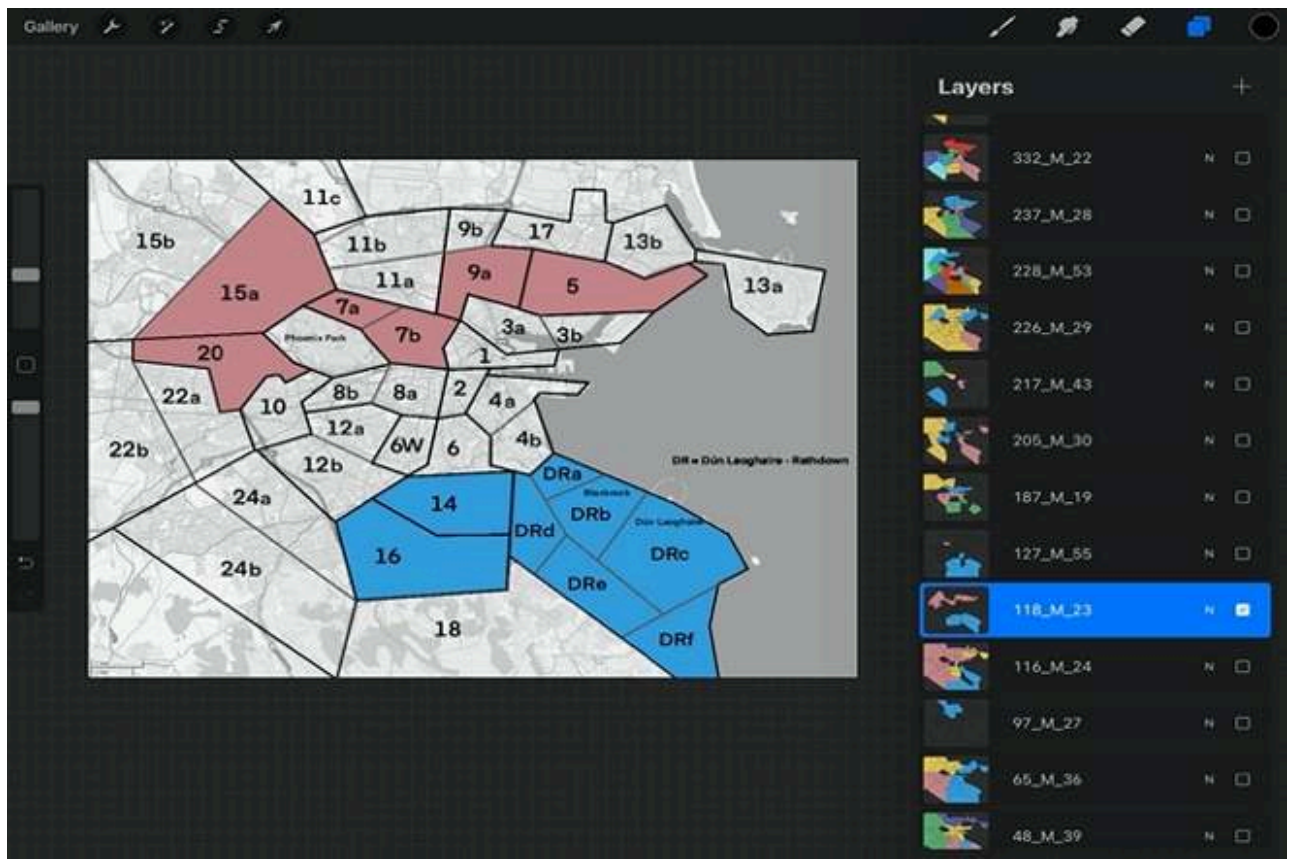

37 Nous avons commencé par créer autant de cartes que de personnes ayant répondu à notre questionnaire. Chacune des cartes a été renommée suivant le code attribué à chaque enquêté ${ }^{20}$. Sur chaque carte figurait les délimitations et sous-divisions des quartiers de Dublin. Nous avons procédé par la suite au remplissage des cartes en fonction des résultats obtenus dans les questionnaires.

Figure 9. - Modélisation sur carte des réponses de l'enquêtée 54_F_28.

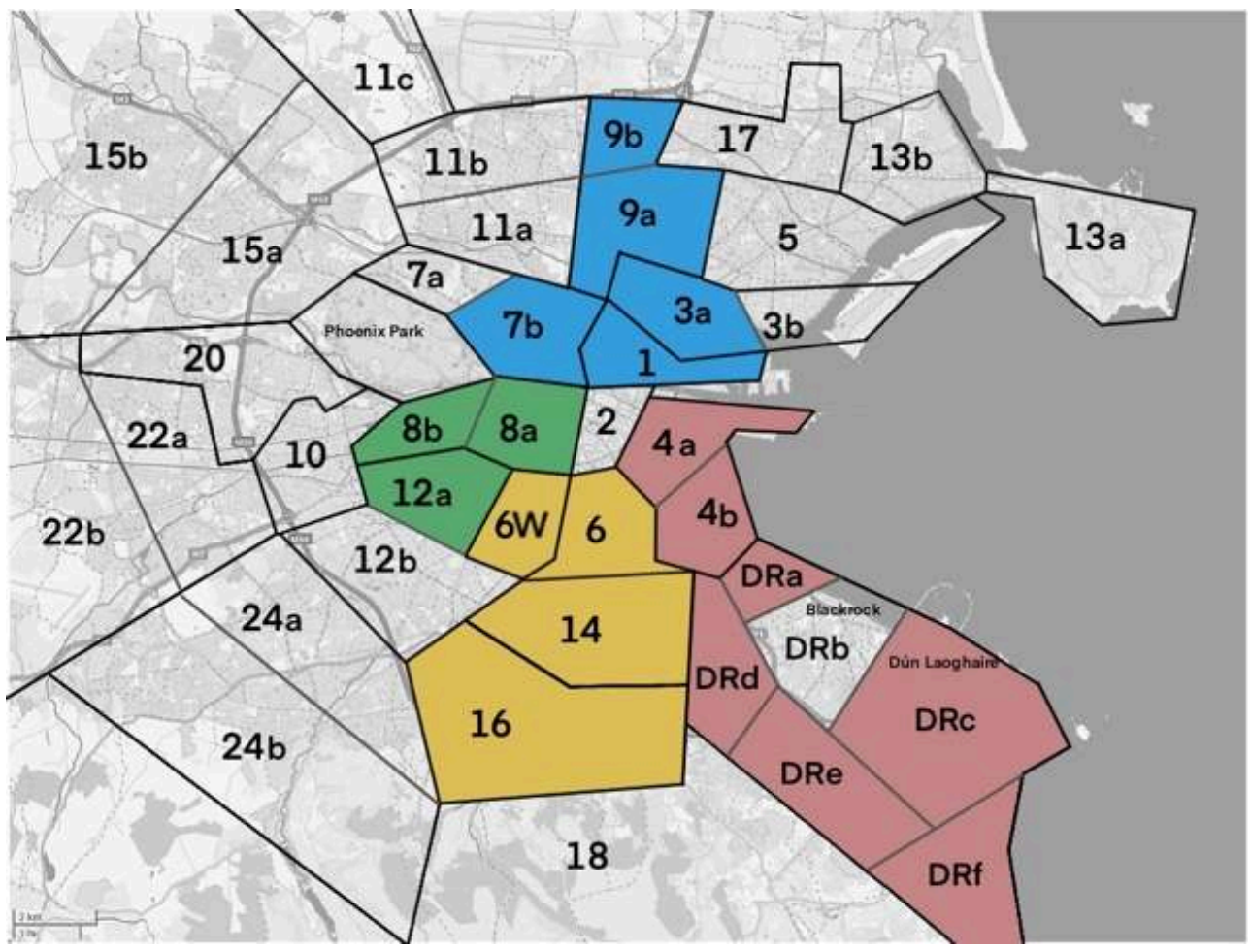


Figure 10. - Modélisation sur carte des réponses de l'enquêté 65_M_36.

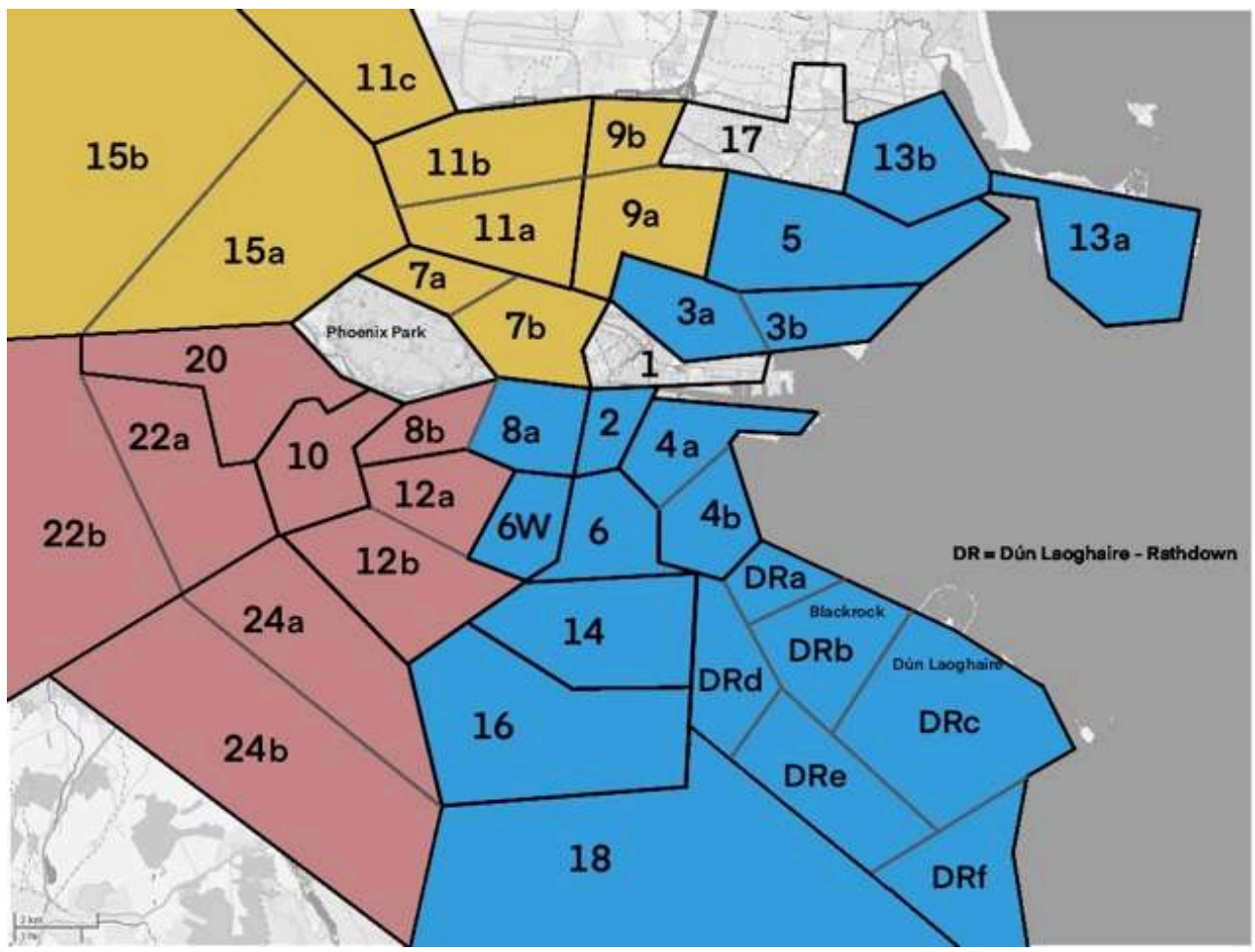

Un code couleur a été adopté pour chaque groupe de zones repérées. Si l'on prend les réponses de l'enquêtée 54_F_28 (fig. 9), le groupe A correspond aux zones bleues (1, 7b, $3 a, 9 a, 9 b)$ tandis que le groupe B correspond aux zones rouges (4a, 4b, DRa, DRc, DRd, DRe, DRf). Ce code couleur est le même pour tous les enquêtés et facilite la distinction entre les différentes variétés perçues ${ }^{21}$. Ainsi, comme on peut le voir ci-dessus, l'enquêtée 54_F_28 a identifié 4 variétés distinctes à Dublin. Quant à l'enquêté 65_M_36, trois variétés se dégagent des résultats (fig. 10).

La création de ce code couleur a présenté un autre avantage pour le traitement de nos données. Nous souhaitions créer des cartes perceptuelles à partir des résultats sur l'évaluation des variétés perçues selon les critères pleasantness et correctness, mais il nous fallait auparavant classer ces résultats. Pour ce faire, nous avons réparti dans un tableur les notes attribuées par les enquêtés à chaque groupe de zones repérées. Chaque groupe correspondant à une couleur (fig. 11), nous avons reporté les couleurs dans le tableur.

Figure 11. - Code couleur attribué à chaque groupe de zones repérées par les enquêtés.
A
B
C
D $\quad E$
$\mathbf{F}$
G H

La figure 12 ci-dessous illustre le classement des notes attribuées par les enquêtées à chaque zone repérée selon le critère pleasantness. D'après les résultats de l'enquêtée 3_F_24, 3 groupes A, B et C - colorés respectivement en bleu, rouge et jaune - sont visibles. Les notes de l'enquêtées selon le critère pleasantness sont réparties comme suit: Groupe $\mathrm{A}=5$; groupe $\mathrm{B}=3$; groupe $\mathrm{C}=3$. L'utilité de ce code couleur est de faciliter le report des nombreuses notes et de limiter autant que possible les erreurs. Après organisation des données, des tests statistiques nous ont permis de tester la solidité de nos données. 
Figure 12. - Classement des notes attribuées par les femmes aux zones repérées en termes de pleasantness.

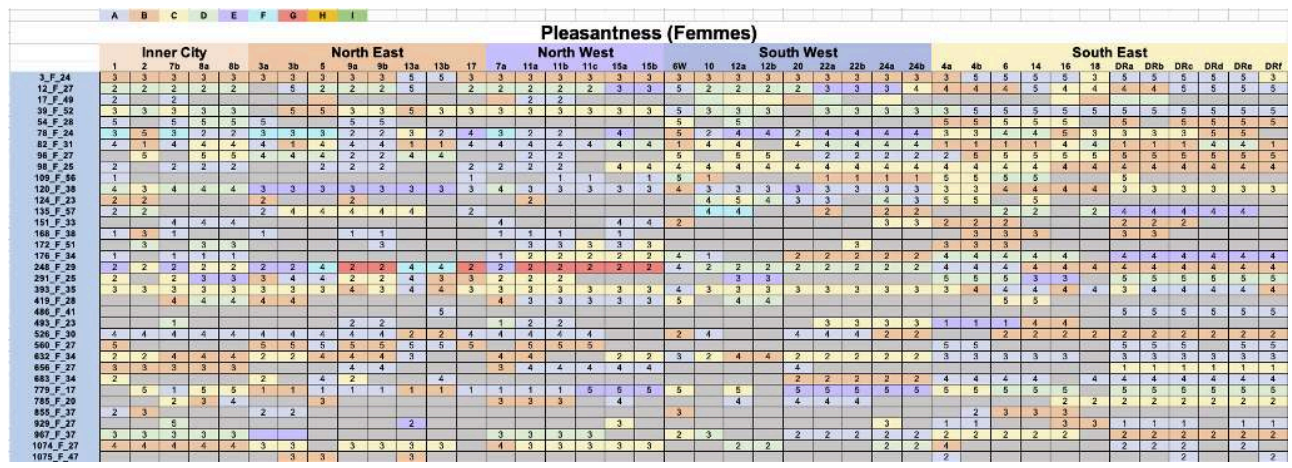

\subsubsection{Les tests statistiques du khi-deux}

41 Deux tests statistiques ont été utilisés pour cette étude : le khi-deux d'ajustement et le khi-deux d'indépendance. Le premier de ces tests, le khi-deux d'ajustement, évalue la représentativité d'un échantillon. Selon Laurencelle (2012: 175), vérifier la représentativité d'un échantillon signifie la vérifier «en démontrant que celui-ci ne s'écarte pas significativement de la répartition proportionnelle des sous-groupes trouvés dans la population ». C'est en ce sens que nous comprenons la notion de représentativité. Le test statistique du khi-deux d'ajustement est utilisé afin de vérifier si les données observées suivent une loi de probabilité attestant de la représentativité de l'échantillon observé.

Le calcul du khi-deux (noté $\chi^{2}$ ) est le suivant :

$$
\chi^{2}=\frac{(O-T)^{2}}{T}
$$

43 Le calcul se lit ainsi « khi-deux = (échantillon observé - effectif théorique) ${ }^{2}$ divisé par l'effectif théorique »

Le $\chi^{2}$ est la valeur obtenue à l'issue du calcul. $T^{22}$ correspond à l'effectif théorique qui est une valeur idéale de laquelle l'échantillon observé, noté 0 , doit se rapprocher le plus possible pour pouvoir être considéré comme représentatif statistiquement. Le test du khi-deux d'ajustement connaît deux issues qui s'expriment selon les hypothèses $\left(\mathrm{H}_{\mathrm{n}}\right)$ suivantes :

- $H_{0}=$ l'échantillon observé est considéré comme représentatif si le khi-deux calculé est inférieur à la valeur critique $\rightarrow \mathrm{H}_{0}$ acceptée $s i \chi^{2}$ observé < valeur critique ;

- $\mathrm{H}_{1}$ = l'échantillon observé n'est pas considéré comme représentatif si le khi-deux calculé est supérieur à la valeur critique $\rightarrow \mathrm{H}_{1}$ acceptée si $\chi^{2}$ observé > valeur critique ;

- la valeur critique est déterminée par le seuil de signification, noté $\alpha$, et le degré de liberté,

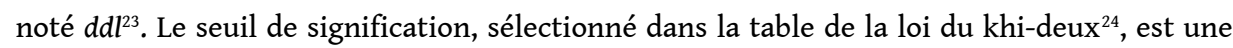
marge d'erreur autorisée souvent déterminée à $5 \%(0,05)$ et à $1 \%(0,01)$. Après avoir sélectionné $\alpha$ et calculé $d d l$, la valeur critique peut être sélectionnée dans la table de la loi du khi-deux.

Quant au test du khi-deux d'indépendance, il mesure l'indépendance $\left(\mathrm{H}_{0}\right)$ ou la dépendance $\left(\mathrm{H}_{1}\right)$ de deux variables qualitatives au sein d'une population à partir de données issues d'un échantillon de cette même population ${ }^{25}$. On calcule la différence 
entre l'effectif théorique $(T)$ et l'effectif observé $(O)$ représenté par notre échantillon. Contrairement au test d'ajustement, $T$ se calcule ainsi :

$T=\frac{\text { Total }_{\text {colonne }} \times \text { Total }_{\text {ligne }}}{\text { Total }}$

Une fois $T$ calculé, il suffit d'appliquer la même opération que pour le test d'ajustement ci-dessus et de vérifier si la valeur totale du khi-deux obtenue est supérieure ou inférieure au seuil de signification.

Une dernière remarque concerne la valeur $p^{26}$ dite " $p$-value». Cette valeur, située entre 0 et 1 , indique la probabilité selon laquelle la distribution de l'échantillon observé serait due au hasard. On définit généralement un seuil critique de $5 \%(p<0,05)$ à ne pas dépasser. Dans le cas où la valeur $p$ est supérieure à ce seuil, on considère qu'il y a de grandes chances que la distribution de l'échantillon observée soit due au hasard et donc que le lien entre les variables observées soit lâche, ce qui reviendrait à valider H0 et à rejeter H1. A contrario, plus la valeur $p$ est faible $(p<0,05)$, plus le lien entre les variables observé est étroit, ce qui reviendrait à rejeter $\mathrm{H} 0$ et valider $\mathrm{H} 1$.

\section{Présentation du corpus d'étude et éléments d'analyses}

\subsection{Le corpus perceptuel d'anglais dublinois contemporain : entre chiffres et cartes}

Au total, 101 réponses jugées complètes par le logiciel LimeSurvey ont été obtenues et 73 sont exploitables. 28 réponses ont été mises de côté, car jugées non pertinentes. Par «non pertinentes » nous entendons que les questionnaires présentent des défauts tels que des réponses partielles, incomplètes ou, parfois, absentes. L'absence répétée de réponses à certaines questions rend difficilement possible la comparabilité des données. De surcroît, certains questionnaires présentaient des réponses qui n'avaient aucun lien avec les questions et qui traduisaient, selon nous, un découragement des utilisateurs quant à la tâche représentée par le questionnaire.

\subsubsection{La répartition hommes/femmes au sein du corpus}

Parmi ces 73 réponses exploitables, 35 femmes et 38 hommes ont répondu au questionnaire. Si ces nombres semblent équilibrés en matière de répartition hommes/ femmes, nous avons souhaité les soumettre à un test du khi-deux d'ajustement afin de nous en assurer. Pour ce faire, nous avons calculé le pourcentage de femmes et d'hommes en Irlande à partir de la population totale de femmes et d'hommes. Ces pourcentages ont ensuite été utilisés afin de calculer dans un second temps les effectifs théoriques (fig. 13). La valeur critique du khi-deux s'élève ici à $3,84^{27}$. Cela signifie que si la valeur du khi-deux calculée sur nos données est inférieure à cette valeur critique, l'échantillon est considéré comme représentatif statistiquement. Le khi-deux total obtenu s'élève à environ 0,112 . Cette valeur se situant bien en deçà de la valeur critique à ne pas dépasser pour pouvoir valider la représentativité de l'échantillon observé, nous pouvons conclure que l'échantillon observé est bien représentatif en matière de répartition hommes/femmes. 


\subsubsection{L'âge des participants} des participants selon l'âge (fig. 15).

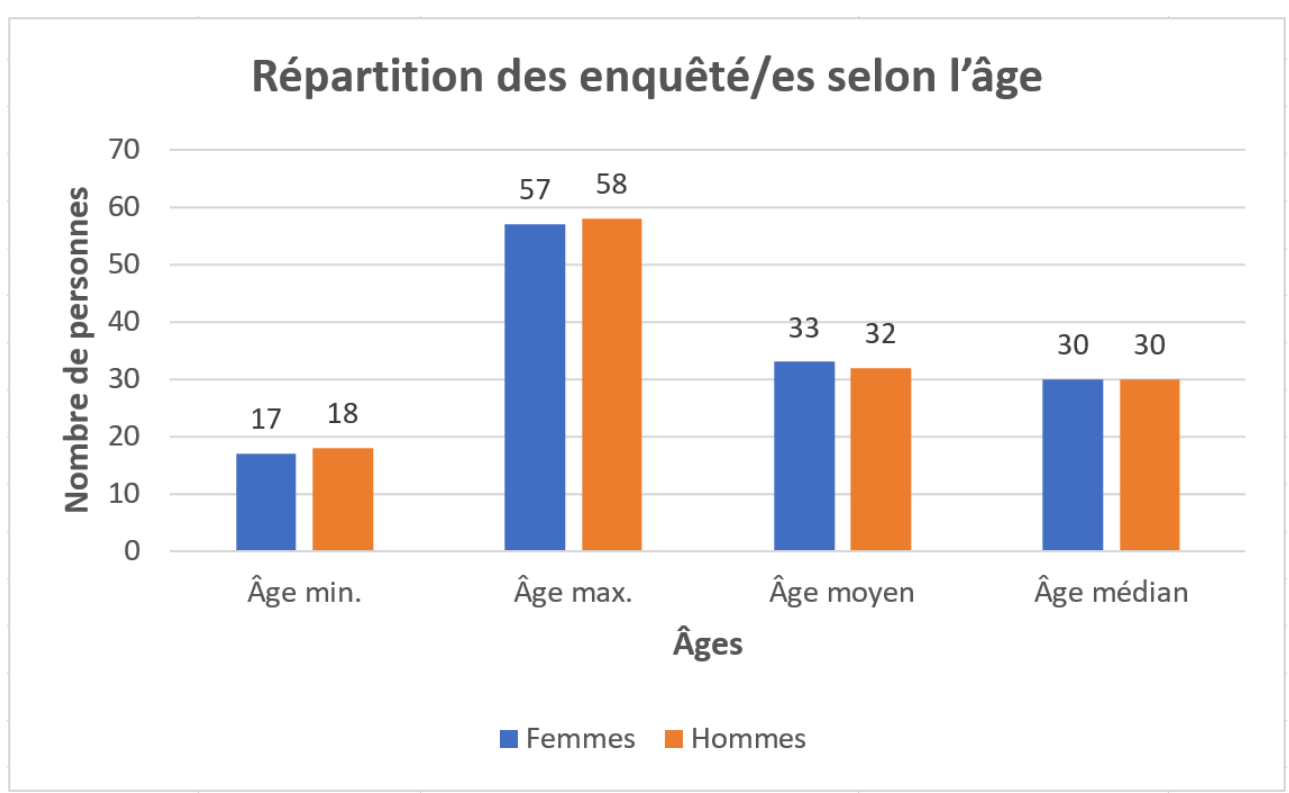

51 On peut voir ci-dessus que l'âge minimum s'élève à 17 ans chez les femmes et 18 ans chez les hommes, tandis que l'âge maximum s'élève à 57 ans chez les femmes et 58 ans chez les hommes. L'âge moyen est de 33 ans pour les femmes et de 32 ans pour les hommes. Toutefois, il importe de noter que le corpus observé n'est pas considéré comme représentatif d'après le test du khi-deux d'ajustement ${ }^{28}$. Notre corpus comporte en grande majorité des enquêtés âgés entre 25 ans et 44 ans (46 enquêtés en tout) mais, sans grande surprise et pour des raisons évidentes, ne comporte aucune donnée de personnes âgées entre 0 et 14 ans. Aucune donnée d'enquêtés de 65 ans et plus ne figure dans le corpus. Le format numérique de cette enquête a vraisemblablement empêché la collecte de données auprès de cette catégorie de personnes ${ }^{29}$. Les données de notre corpus proviennent donc d'enquêtés âgés de 17 ans à 58 ans.

\subsubsection{Le niveau d'études}

Parmi les enquêtés interrogés, on remarque que seulement 2 hommes possèdent un niveau inférieur à un équivalent $\mathrm{BAC}^{30}$, tandis que 5 femmes et 5 hommes possèdent un niveau équivalent BAC. 
Figure 14. - Répartition des enquêté/es selon le niveau d'études.

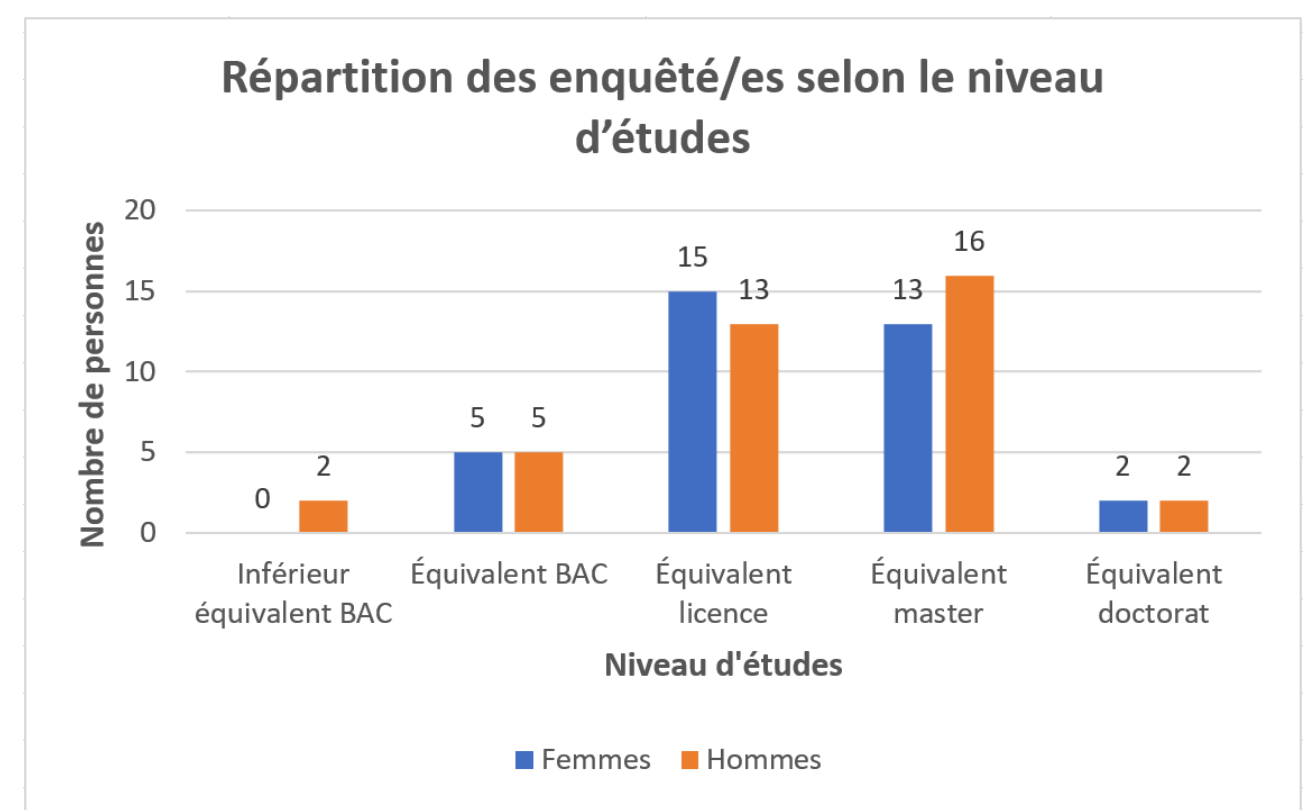

On constate ci-dessus (fig. 16) que la majeure partie des enquêtés possèdent un niveau d'études équivalent à une licence ou un master. Enfin, 2 femmes et 2 hommes possèdent un niveau équivalent à un doctorat. C'est donc sans surprise que nous constatons une prépondérance d'enquêtés ayant un niveau d'études supérieur à un niveau BAC. Cela pourrait certainement s'expliquer en raison de la spécificité et la nature métalinguistique de l'enquête (interrogation sur la perception linguistique).

\subsubsection{Les lieux de naissance et de résidence}

Le caractère anonyme de l'enquête empêche la collecte d'informations concernant le lieu de vie exact des enquêtés. Les résultats ci-dessous (fig. 17) montrent une vue globale de la répartition des enquêtés selon le lieu de naissance. 
Figure 15. - Répartition des enquêté/es selon le lieu de naissance.

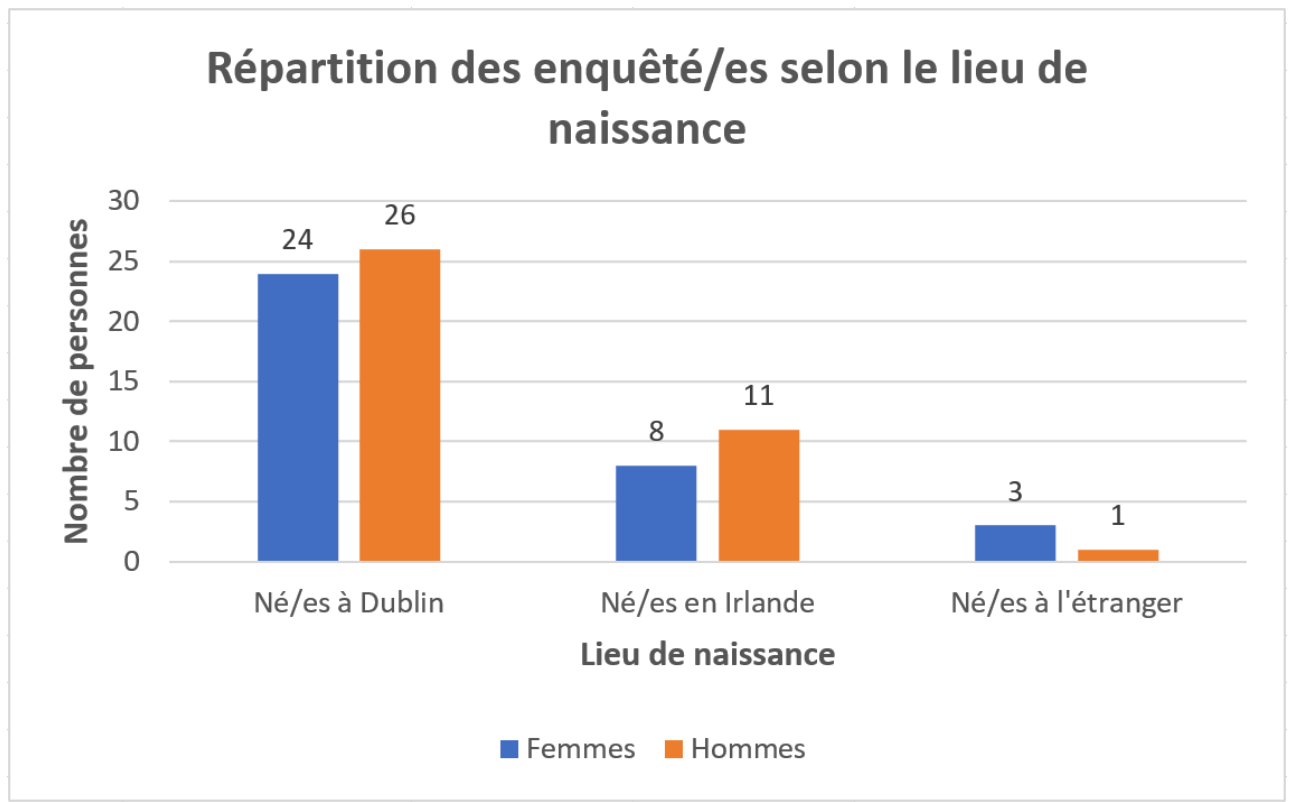

Ainsi, on peut constater qu'une très grande majorité des personnes enquêtées vivant à Dublin sont nées à Dublin. Une petite partie ( 8 femmes et 11 hommes) est née en Irlande et seulement 3 femmes et 1 homme sont nés à l'étranger.

Quant au lieu de résidence, les métadonnées obtenues dans notre corpus ont servi à la création des cartes suivantes :

Figure 16. - Répartition des femmes selon leur lieu de résidence.

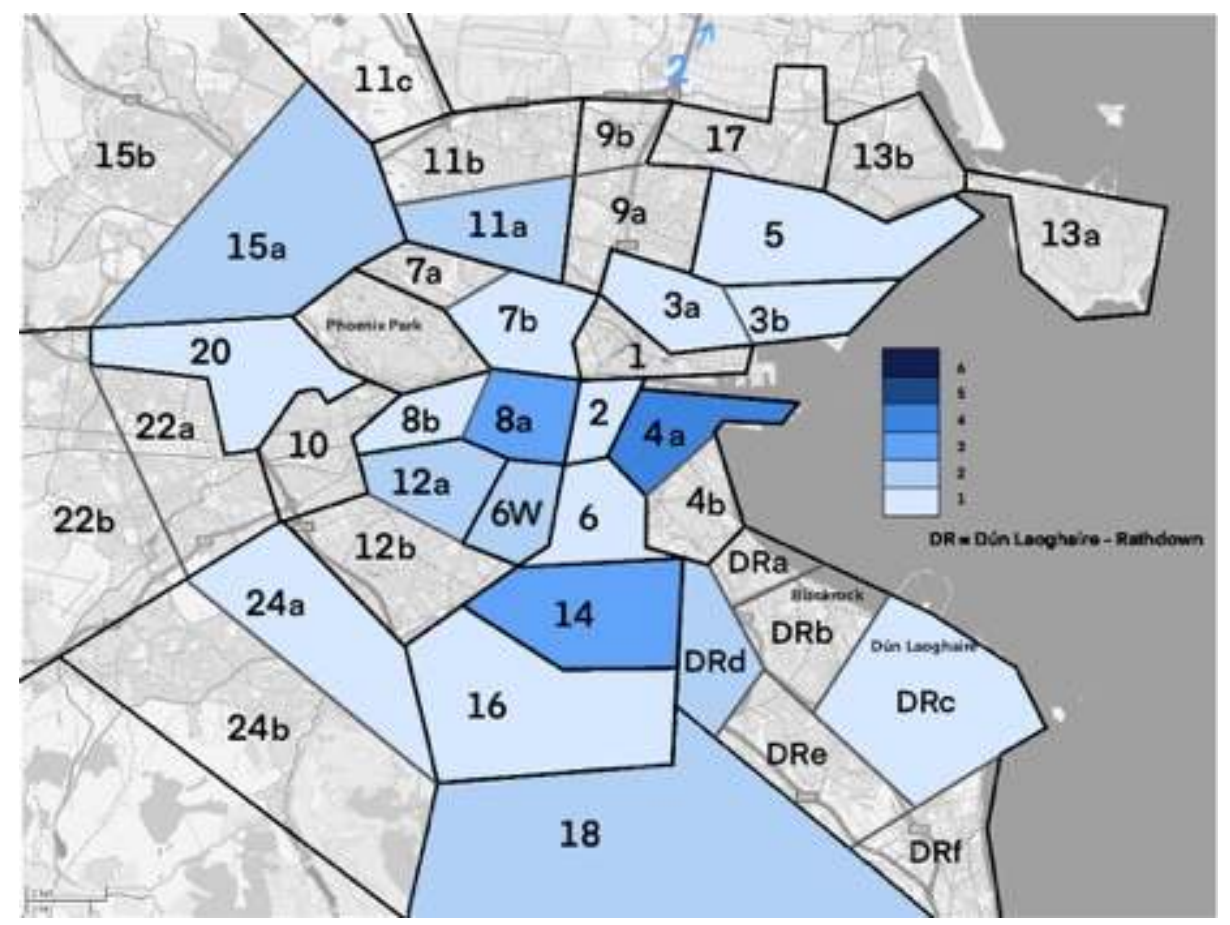


Figure 17. - Répartition des hommes selon leur lieu de résidence.

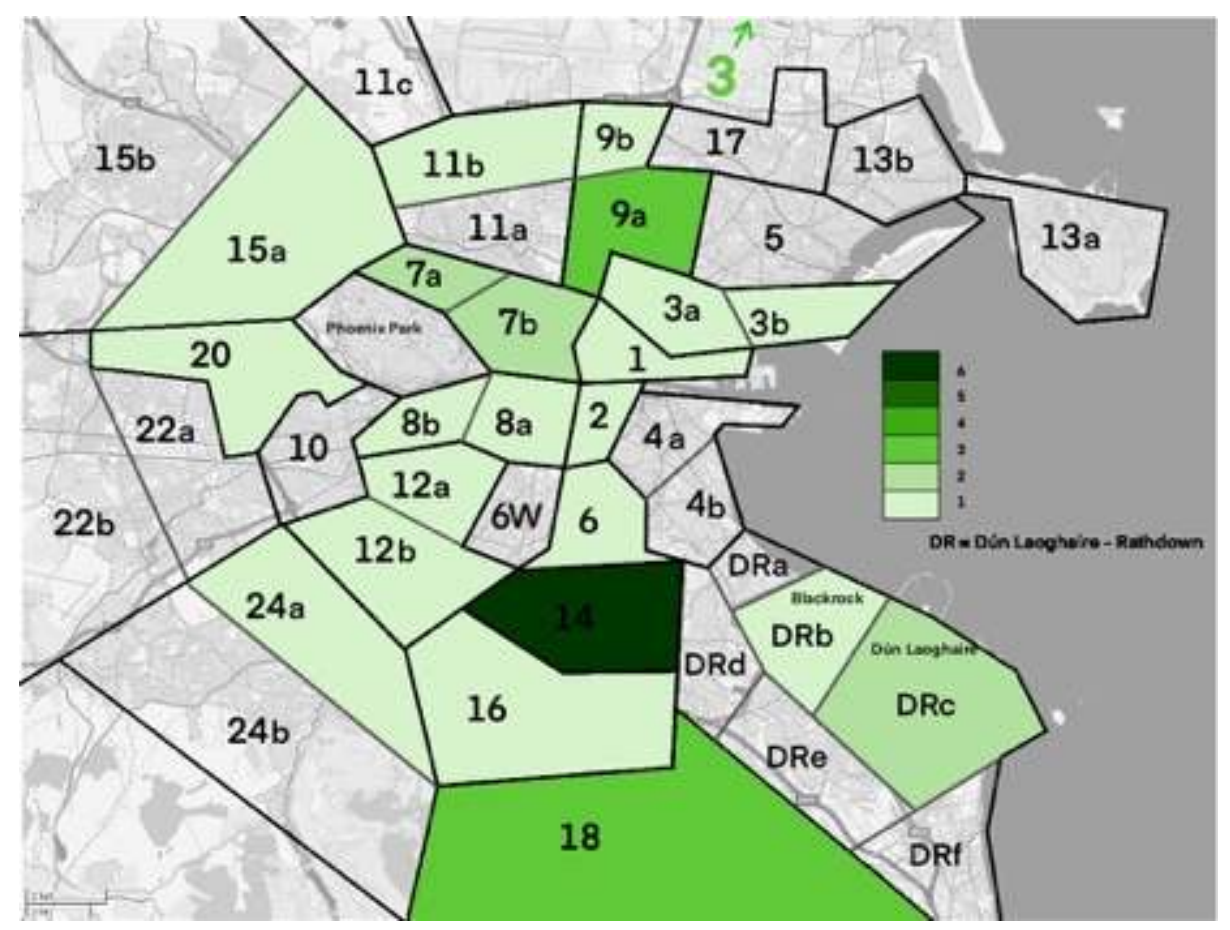

Figure 18. - Répartition des enquêtés (femmes et hommes) selon leur lieu de résidence ${ }^{31}$.

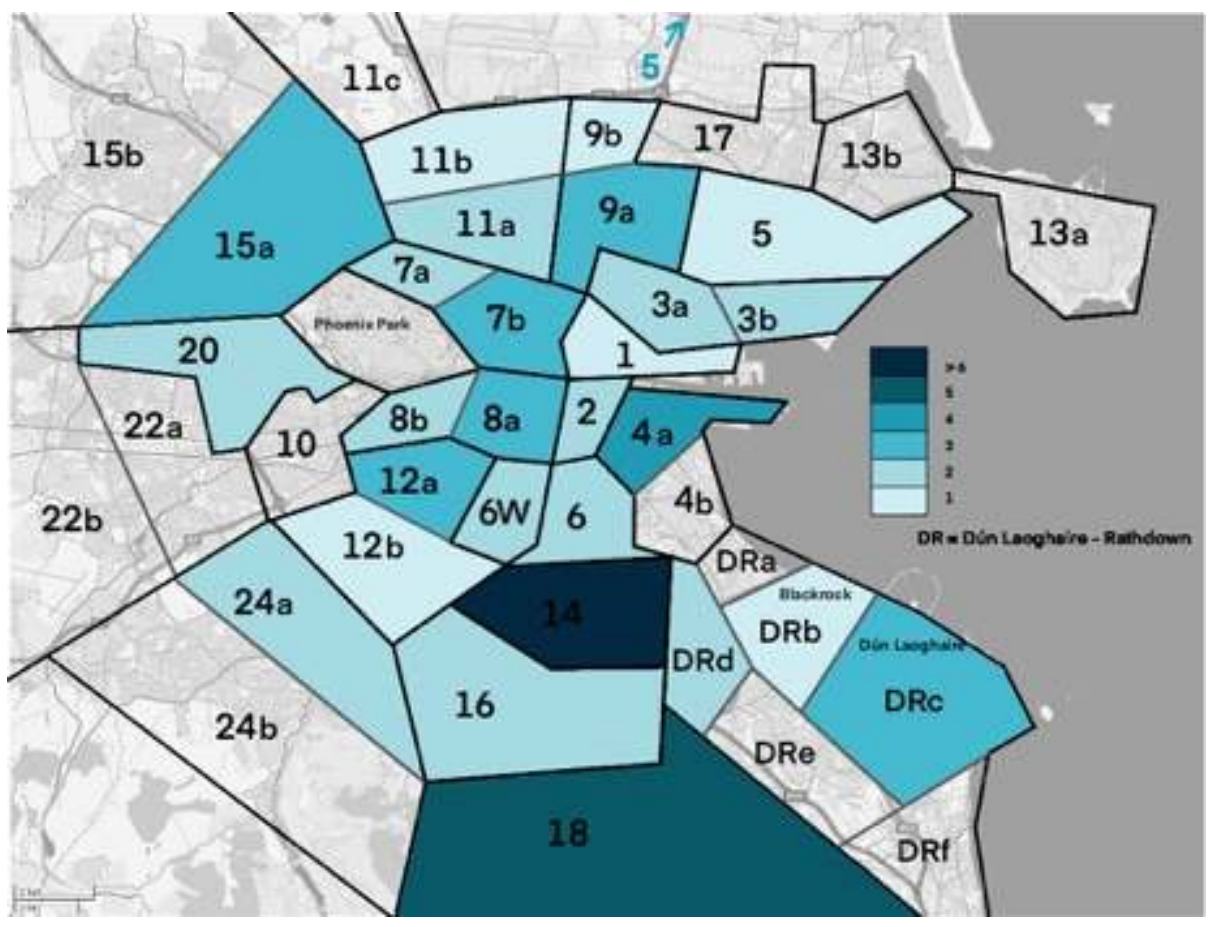

57 On peut donc constater sur les cartes ci-dessus que la répartition des enquêtés selon leur lieu de résidence est, somme toute, équilibrée. 


\subsection{Le corpus perceptuel de l'anglais dublinois contemporain en quelques résultats}

On constate qu'une majorité d'enquêtés a repéré de 3 à 5 variétés au cours de la tâche de dessin sur fond de carte (fig. 21).

Figure 19. - Nombre total de zones repérées par les enquêté/es.

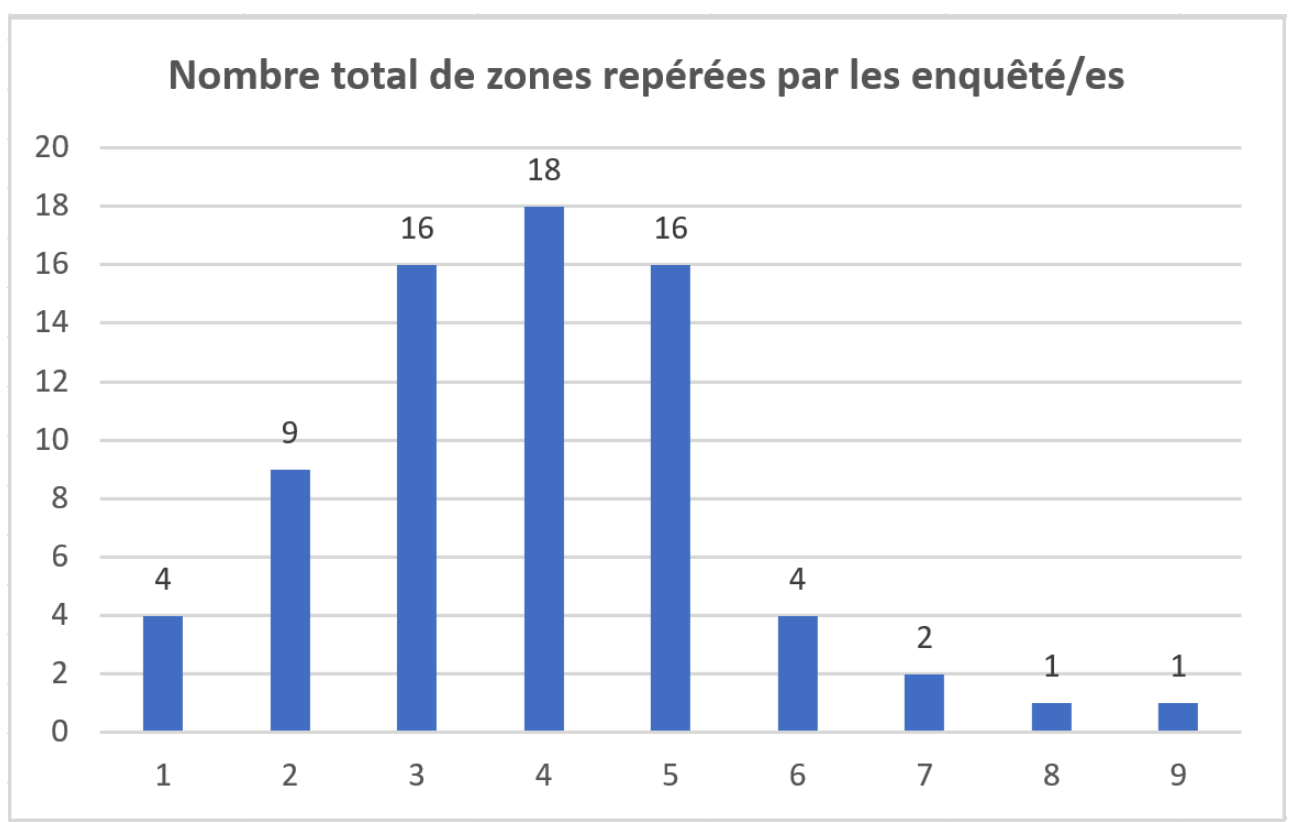

D'autres enquêtés ont repéré jusqu'à 9 variétés au total, ce qui semble montrer qu'un consensus au sein des Dublinois a du mal à se dégager quant au nombre de variétés perçues. D'après Lonergan (2013: 120), cela est révélateur des limites de la tâche de repérage qui ne peut capturer la subtilité des nuances établies par les enquêtés. Nous avons pu néanmoins remarquer une certaine régularité dans la fréquence de repérage des quartiers (ou districts) de Dublin comme on peut le voir ci-dessous :

Figure 20. - Quartiers de Dublin repérés par les locutrices et locuteurs interrogé/es.

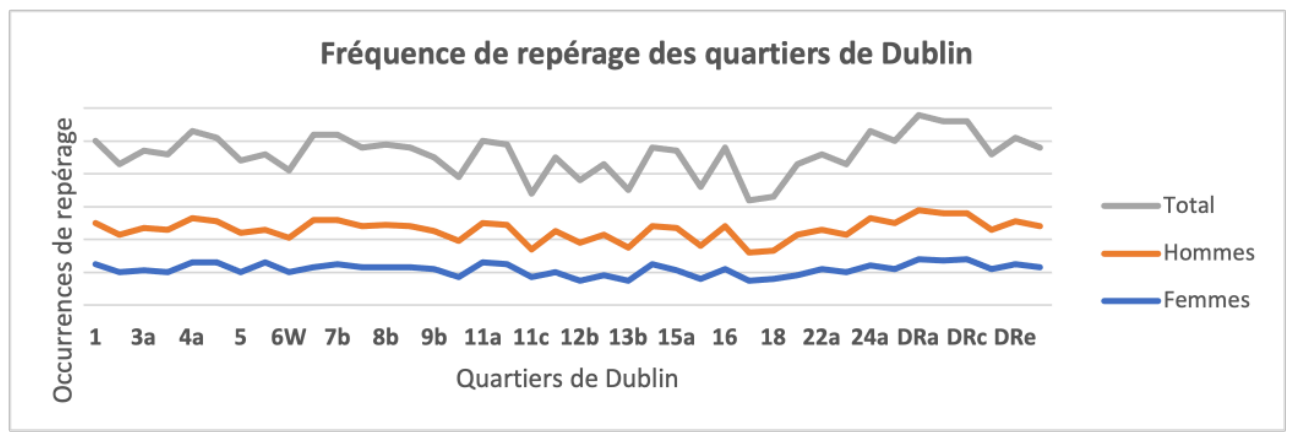

On constate que les tendances prises par les courbes du côté des femmes et des hommes sont sensiblement les mêmes et sont régulières. Cela signifie que chaque quartier $a$, en moyenne, été désigné autant de fois par les femmes que par les hommes comme faisant partie d'une zone d'importance. D'après le test du khi-deux d'indépendance, il n'existe pas de lien entre les variables ${ }^{32}$ « sexe » et « fréquence de repérage ». 
61 entre le lieu de naissance et la fréquence de repérage des districts. Ainsi, que l'on soit Dublinois de naissance ou non, les quartiers les plus saillants en termes de variétés sont les mêmes. L'on pourrait ici émettre l'hypothèse que la perception de différentes variétés au sein d'un espace géographique semble dépendante de la durée de vie dans cet espace $^{34}$ et non de la provenance géographique. Cette affirmation peut sembler évidente aux premiers abords, mais nous pensons qu'il est essentiel de le souligner, car plusieurs enquêtés ne sont pas des anglophones natifs, ce qui ne semble pas influer sur la fréquence de repérage. Cette remarque est, selon nous, révélatrice du rôle prépondérant que joue l'empirisme géo-linguistique dans la perception linguistique.

Figure 21. - Occurrences de repérages des quartiers de Dublin par les femmes (plus une zone est foncée, plus elle a été repérée par les enquêtées).

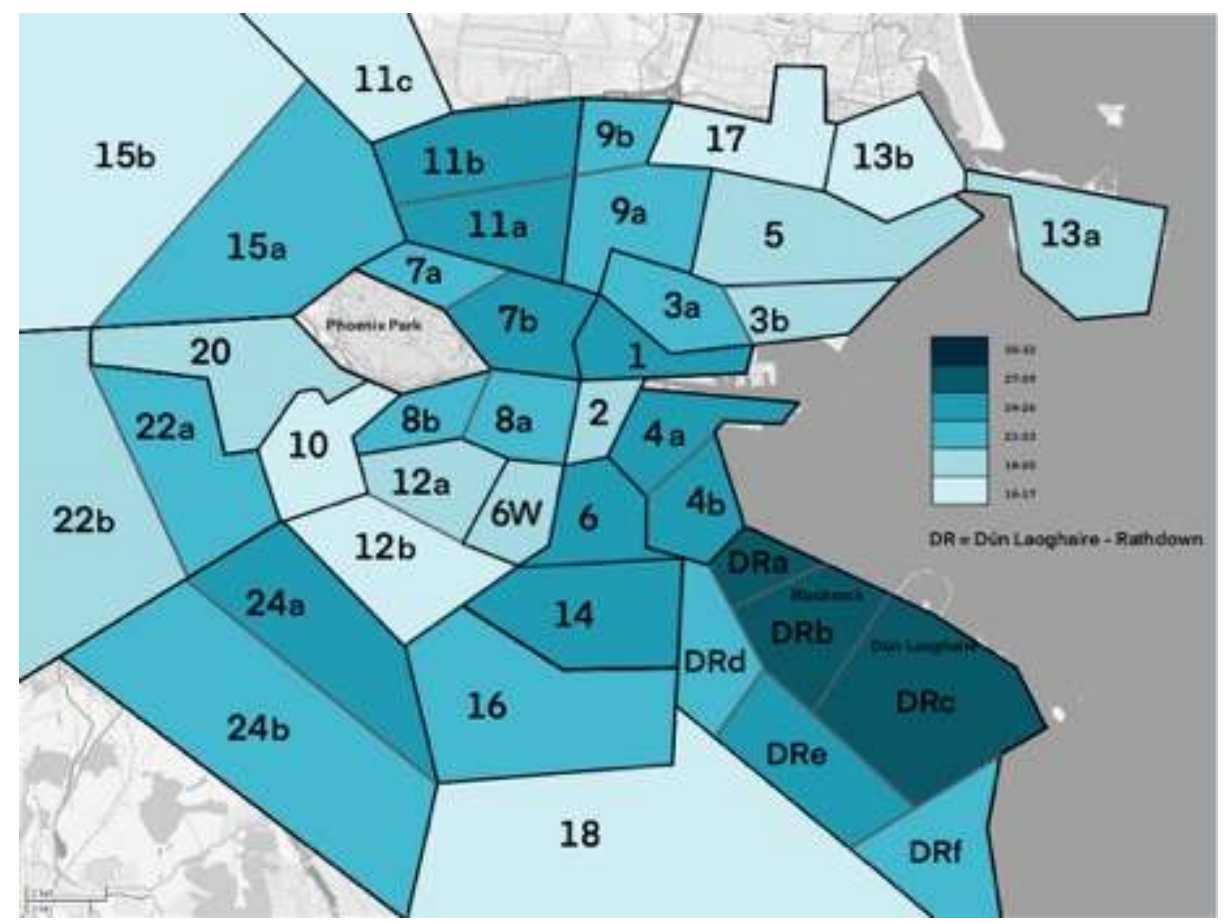


Figure 22. - Occurrences de repérages des quartiers de Dublin par les hommes (plus une zone est foncée, plus elle a été repérée par les enquêtés).

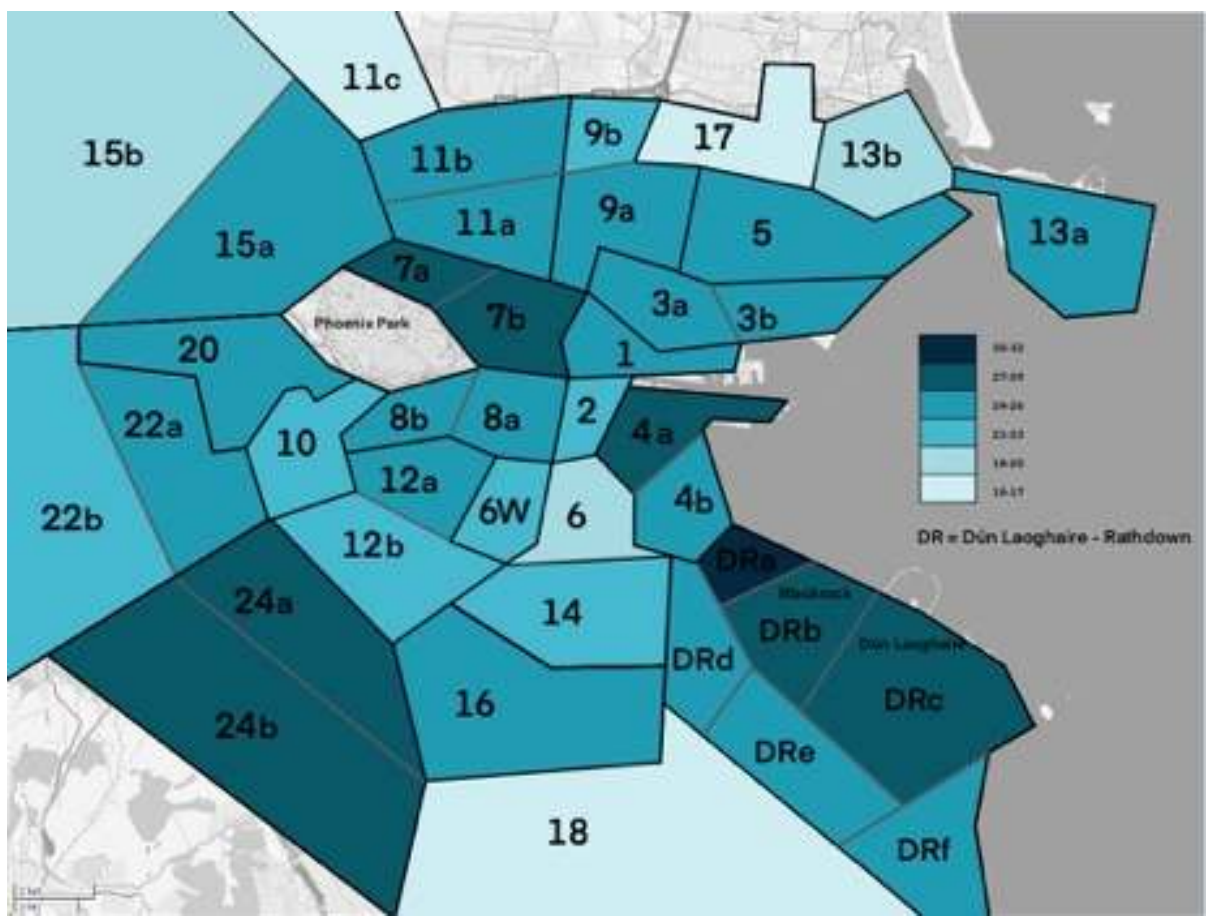

Figure 23. Total des occurrences de repérages des quartiers de Dublin par les femmes et les hommes (plus une zone est foncée, plus elle a été repérée par les enquêté/es).

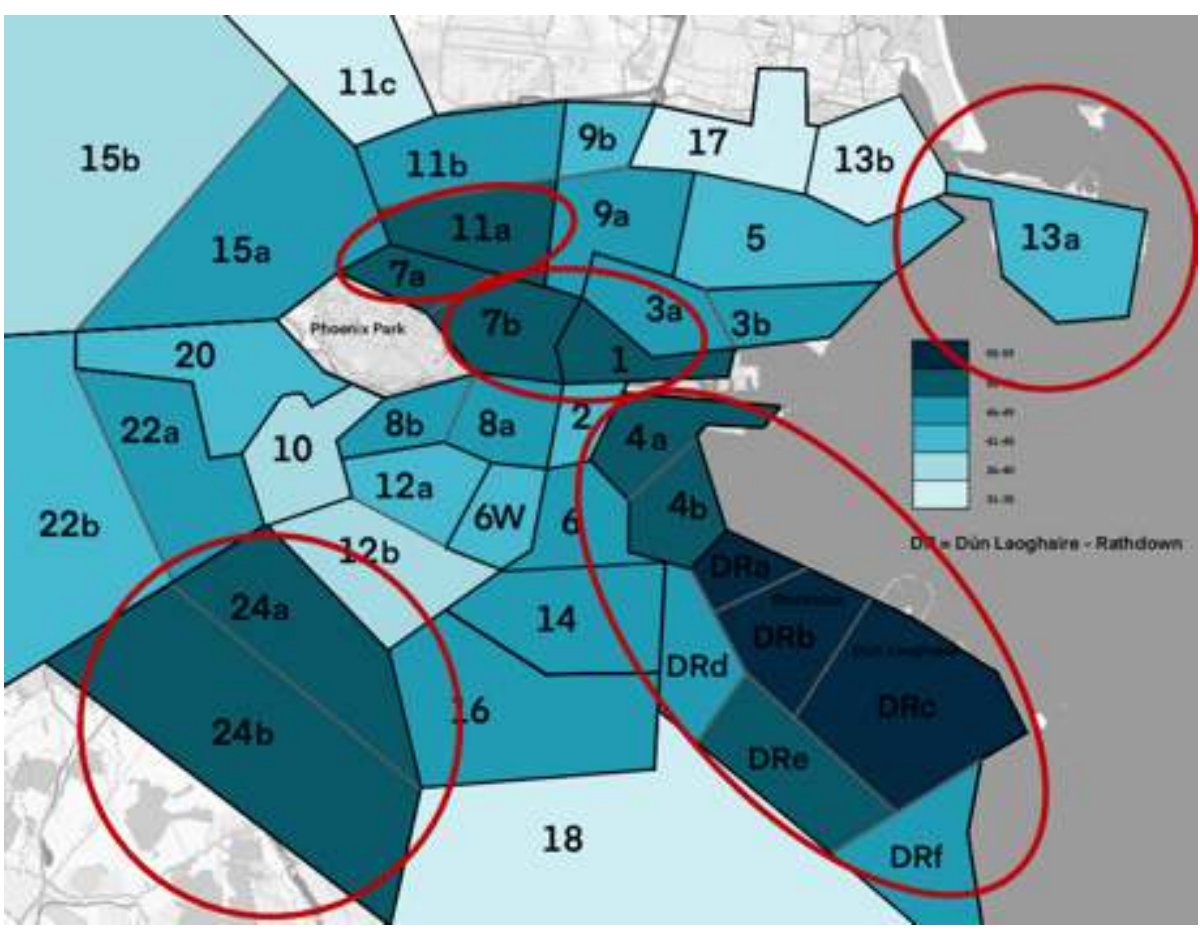

63 On peut voir (fig. 25) se démarquer cinq zones, au centre, au nord-ouest, au sud-ouest et au sud-est de Dublin. Une cinquième zone (13a) a été entourée, car l'on a constaté à plusieurs reprises une association de cette zone à celle située dans le sud-est de la ville. Pour un certain nombre de locuteurs, il existerait une continuité de la variété parlée 
dans le sud-est de la ville qui s'étendrait jusqu'à cette zone au nord-est. Il nous a donc semblé pertinent de l'entourer sur la carte. Les cartes mettent en évidence cinq grandes variétés symbolisées par les cercles rouges ci-dessus. Une enquête de terrain plus approfondie serait nécessaire afin d'enregistrer et comparer les productions orales de locutrices et locuteurs vivant dans ces zones. Nous avions également demandé aux enquêté/es d'évaluer les variétés perçues en matière de pleasantness et correctness :

Figure 24. - Répartition des notes attribuées par les femmes aux différents quartiers repérés selon le critère pleasantness (plus une zone est foncée, plus la note attribuée est élevée).

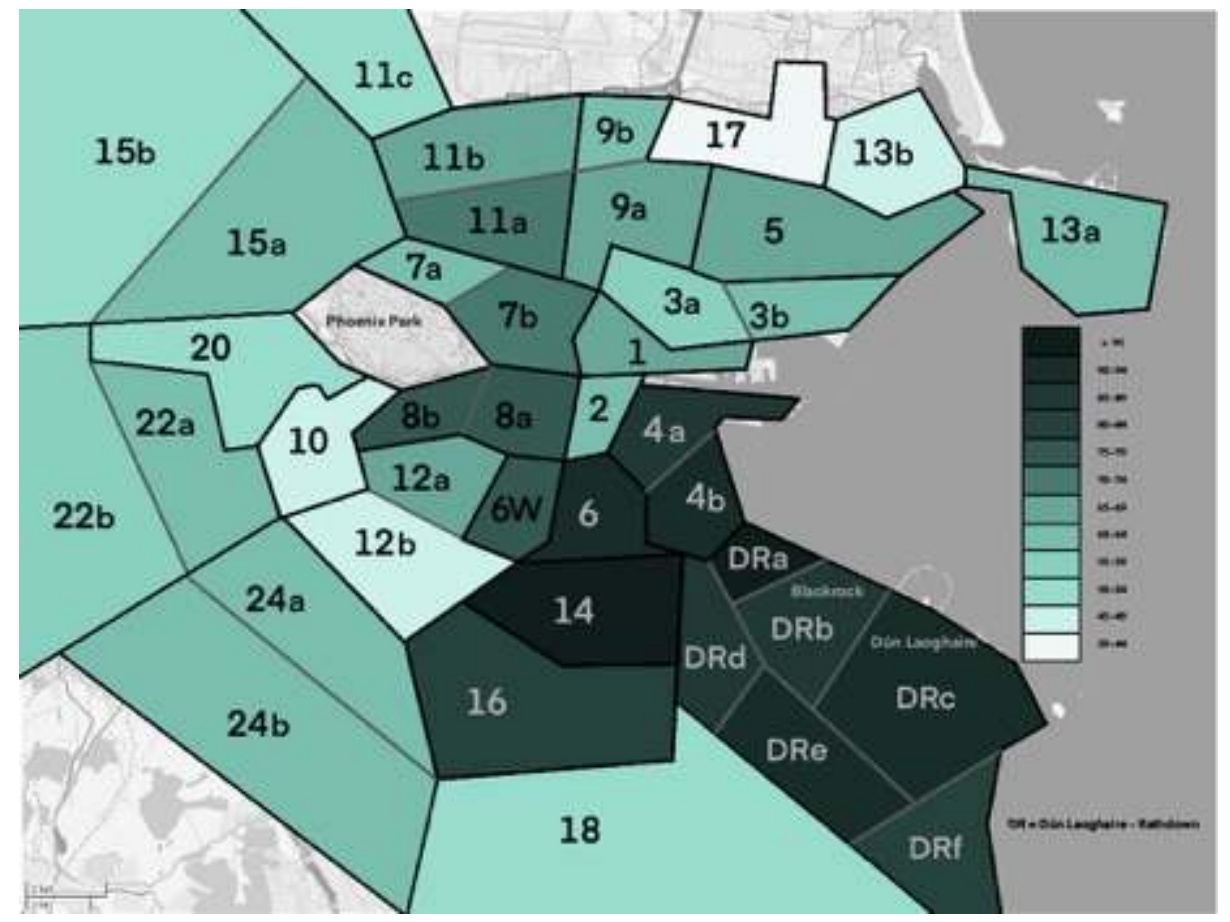


Figure 25. - Répartition des notes attribuées par les hommes aux différents quartiers repérés selon le critère pleasantness (plus une zone est foncée, plus la note attribuée est élevée).

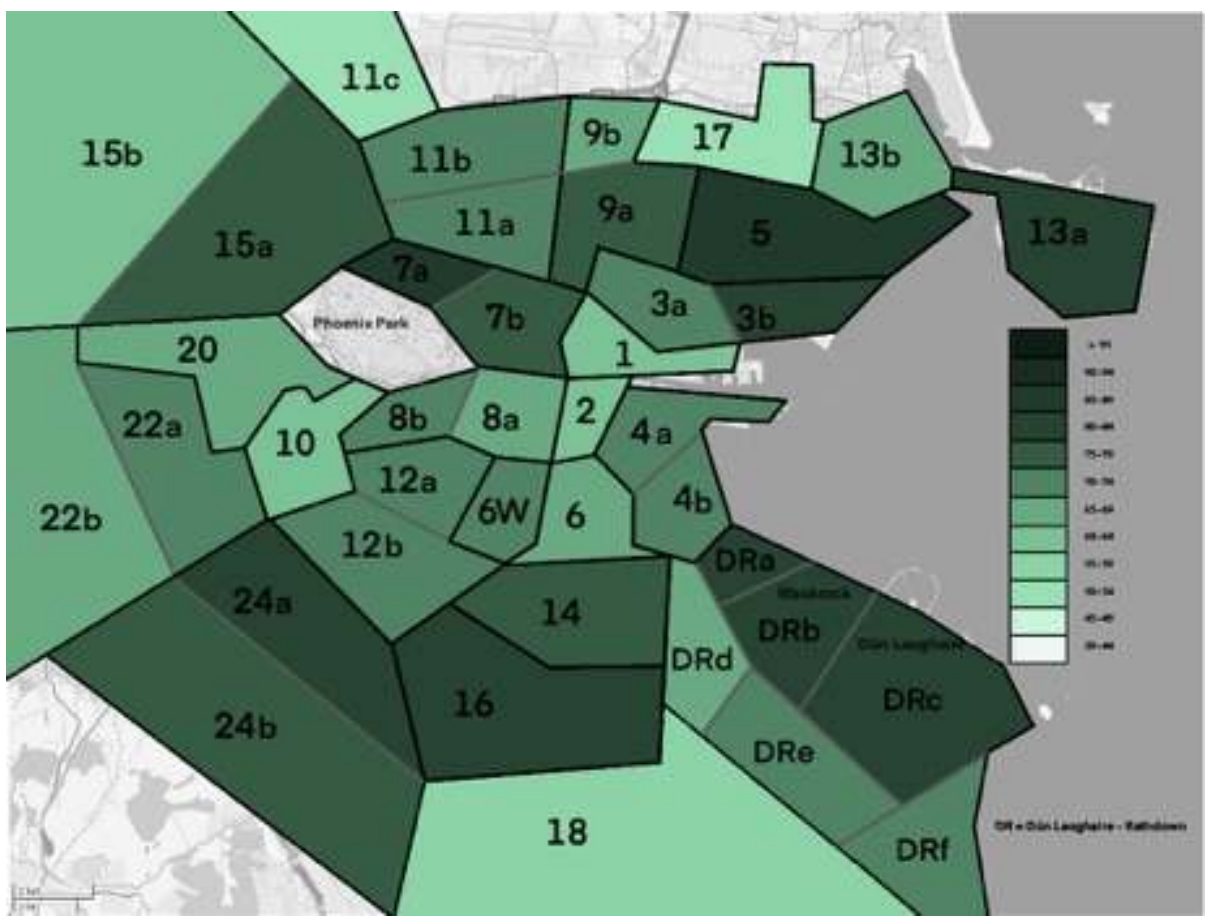

Figure 26. - Répartition des notes attribuées par les femmes et les hommes aux différents quartiers repérés selon le critère pleasantness (plus une zone est foncée, plus la note attribuée est élevée).

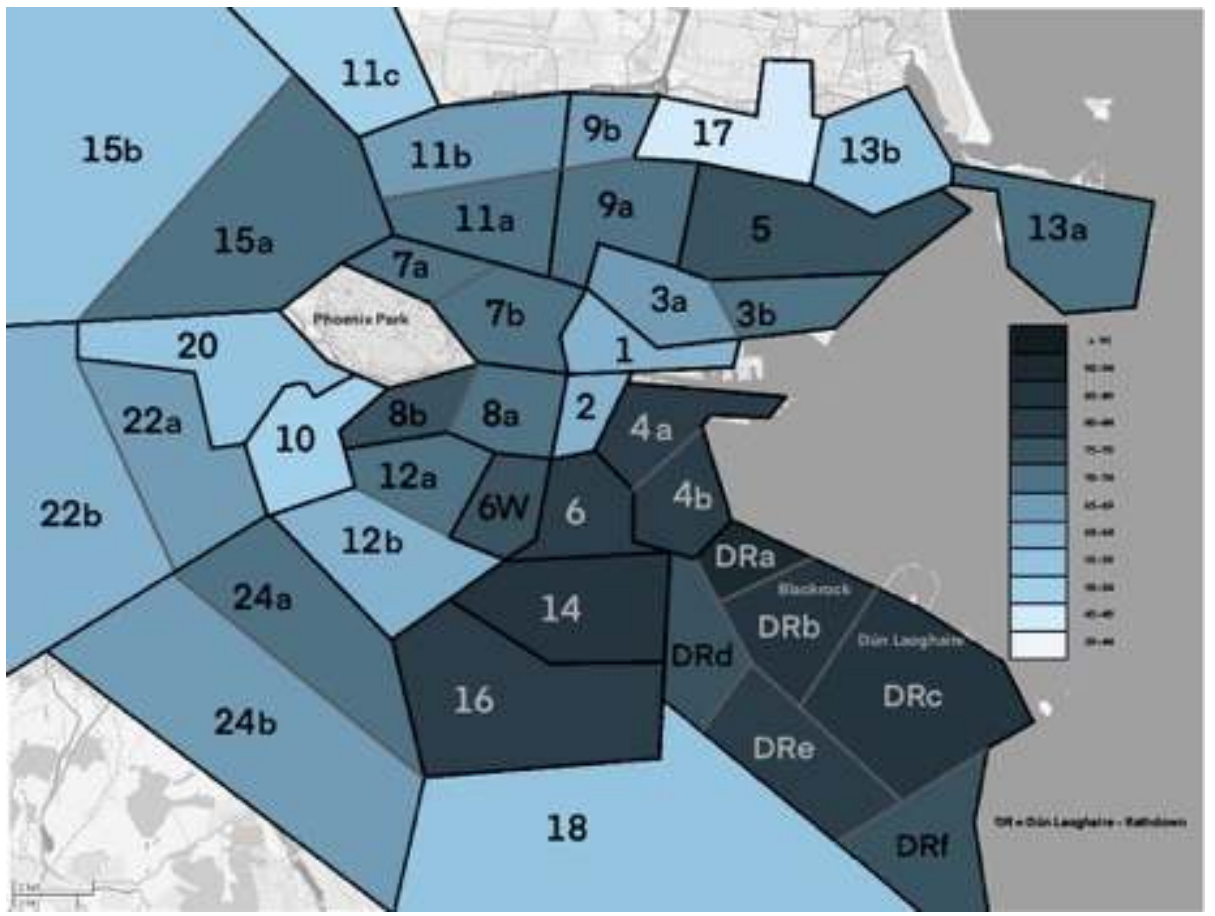


Figure 27. - Répartition des notes attribuées par les femmes aux différents quartiers repérés selon le critère correctness (plus une zone est foncée, plus la note attribuée est élevée).

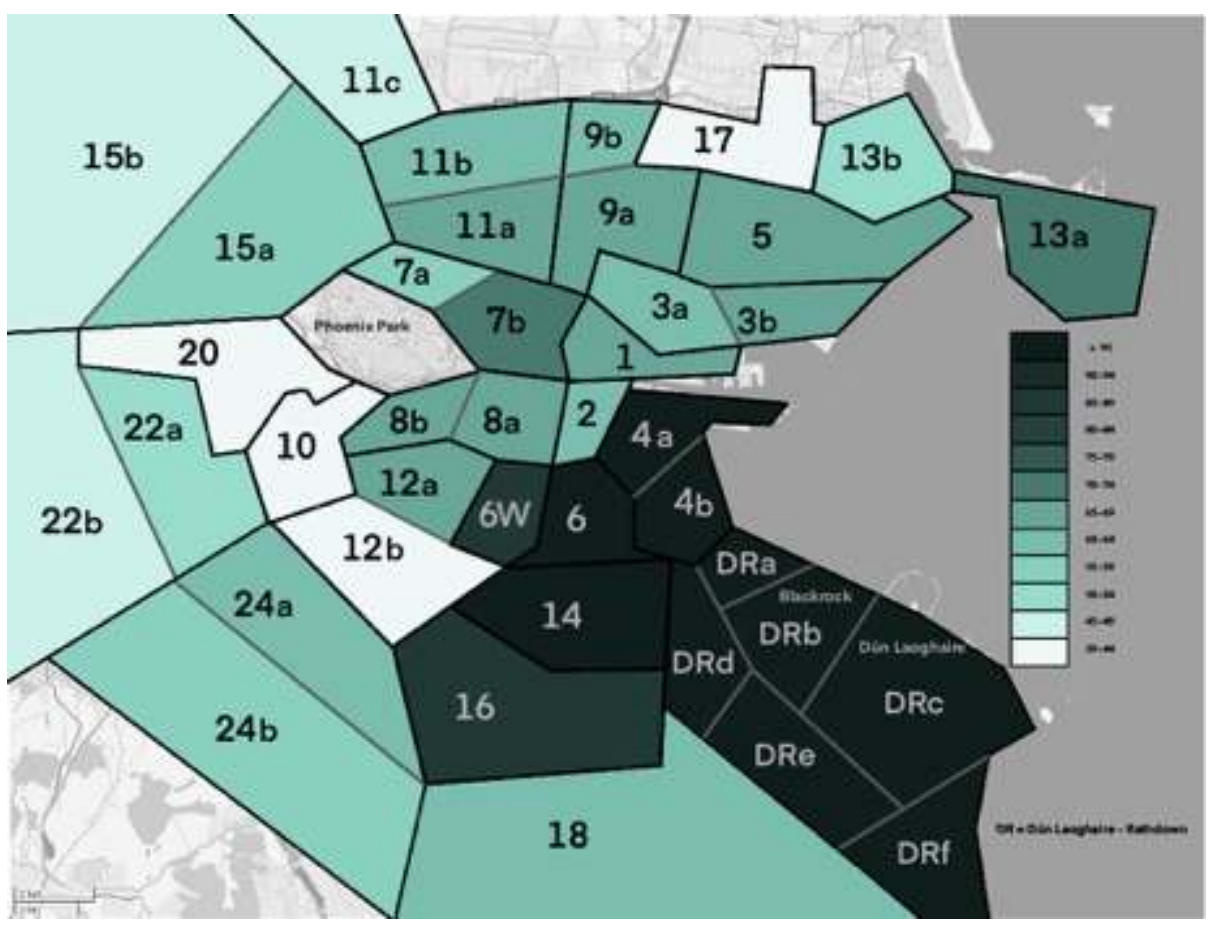

Figure 28. - Répartition des notes attribuées par les hommes aux différents quartiers repérés selon le critère correctness (plus une zone est foncée, plus la note attribuée est élevée).

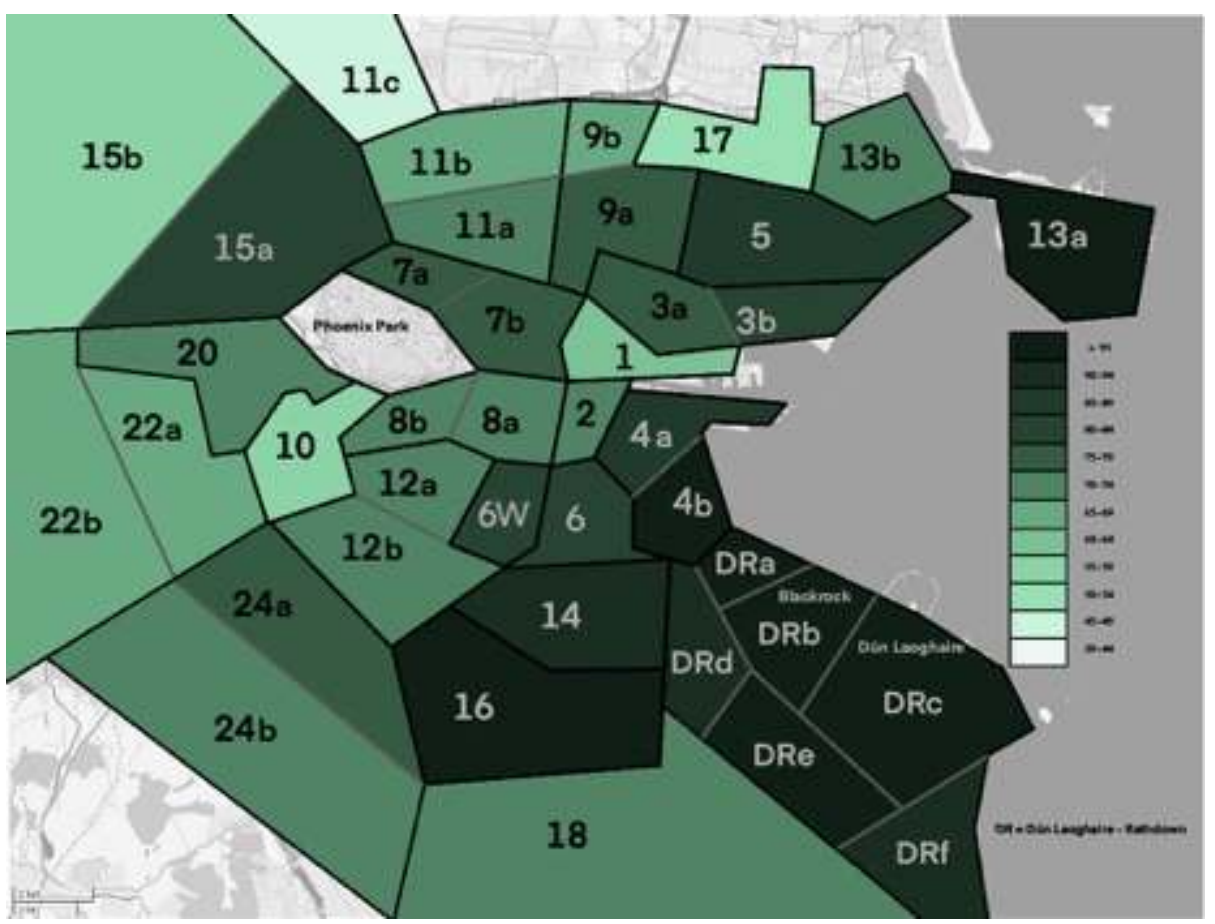


Figure 29. - Répartition des notes attribuées par les femmes et les hommes aux différents quartiers repérés selon le critère correctness (plus une zone est foncée, plus la note attribuée est élevée).

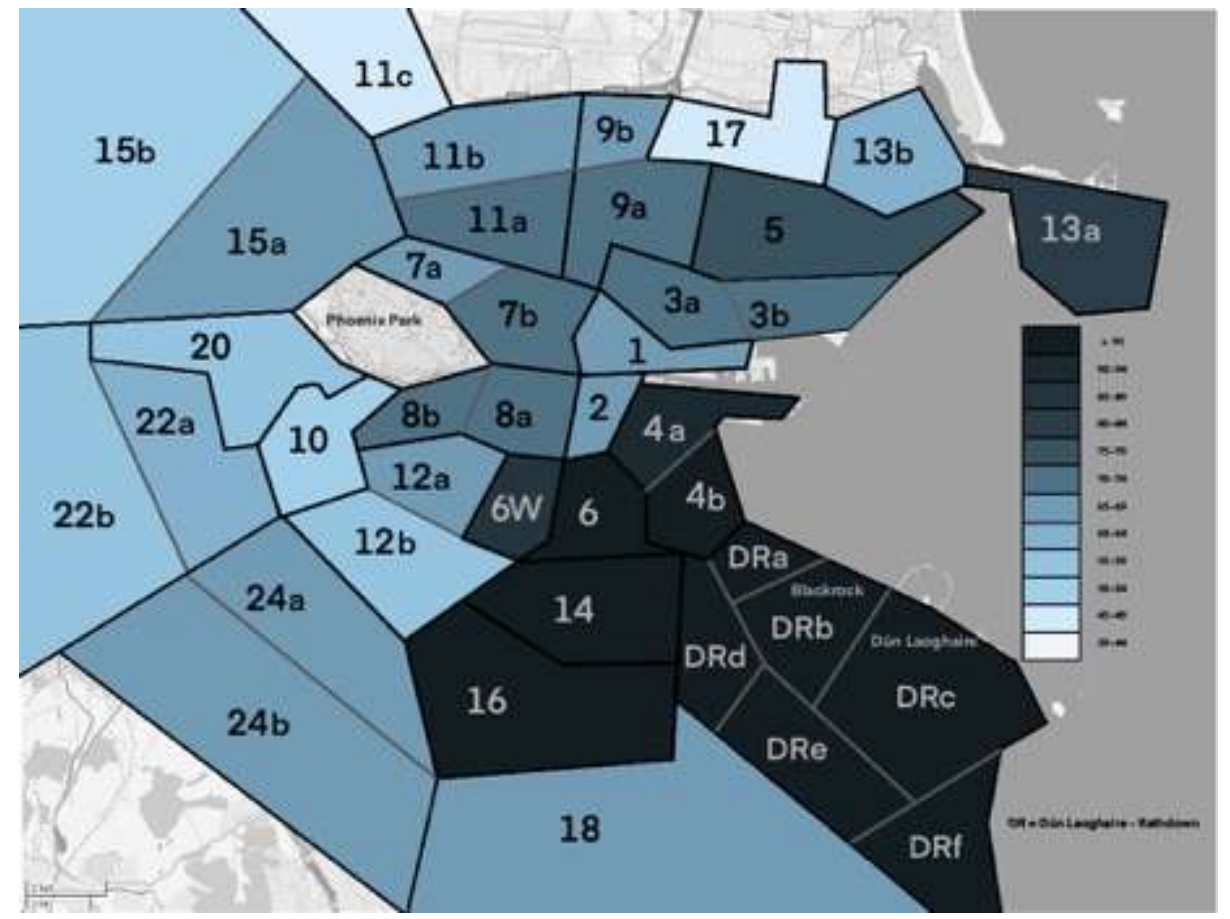

On constate que la zone au sud-est de Dublin obtient des notes élevées en matière de pleasantness et correctness; de plus, il semble exister une différence entre les femmes et les hommes quant au critère pleasantness. Les notes attribuées par les hommes sont moins concentrées au sud-est de la ville contrairement aux notes attribuées par les femmes. Nous tenons à noter que, statistiquement, il semble exister un lien de dépendance entre les variables "sexe» et "pleasantness " ${ }^{35}$ et "sexe» et "correctness $»^{36}$. De plus, d'après les cartes ci-dessus (fig. 28 et 31), il semblerait également y avoir une relation étroite ${ }^{37}$ entre pleasantness et correctness qui témoigne de l'influence que ces variables ont l'une sur l'autre.

Enfin, une brève analyse prosodique et sémantique ${ }^{38}$ de quelques commentaires métalinguistiques permet de mettre en évidence l'ambivalence avec laquelle la variété au sud-est de Dublin est perçue :

-[1] Posh and grating ;

-[2] Posh but in a very annoying way ;

- [3] Posh, pretentious ${ }^{39}$.

On remarque dans les exemples ci-dessus que posh, adjectif dont la connotation s'imprègne de son cotexte, est connoté négativement par la présence d'adjectifs tels grating, annoying et pretentious. Cela est d'autant plus surprenant compte tenu des notes élevées attribuées à la variété au sud-est. En revanche, les commentaires métalinguistiques semblent suivre la tendance des notes attribuées au nord, au sud-ouest et au centre-ville qui sont décrits comme rough, harsh ou encore hard ${ }^{40}$. 


\section{Conclusions et perspectives}

67 Le parti pris de cet article a été d'utiliser la dialectologie perceptuelle comme outil permettant, dans une étude variationniste, de rendre compte de la diversité des variétés parlées dans l'espace urbain dublinois. Le contexte de pandémie dans lequel cette étude a été menée a servi de moteur à la réflexion sur les apports du numérique à une discipline dans laquelle les enquêtes sont menées traditionnellement sur le terrain.

Les quelques résultats présentés en troisième partie, principalement sous forme de cartes, montrent, nous l'espérons, tout l'intérêt d'une enquête perceptuelle au format numérique, de par la simplification de certaines tâches qui peuvent parfois s'avérer techniques. L'objectif de ce travail n'est pas de démontrer que le numérique peut aisément supplanter le terrain et le contact humain, mais simplement d'argumenter en faveur du numérique comme une alternative au terrain le cas échéant. La forte présence du numérique dans notre quotidien nous pousse inéluctablement à nous interroger sur ses limites, mais aussi sur les possibilités qu'il offre. Compte tenu du coût humain qu'une telle enquête représente, deux tâches ont guidé notre étude. L'objectif premier de cette enquête était d'interroger la perception des locutrices et locuteurs dublinois afin d'identifier des zones d'investigation d'intérêt. Ce travail sert de point de départ à une étude socio-phonologique et acoustique de l'anglais dublinois contemporain de plus grande envergure et montre que la dialectologie perceptuelle peut s'inscrire dans une réflexion plus large permettant au chercheur de préparer le terrain.

Cette étude étant exploratoire, il va de soi qu'elle ne peut être prise comme protocole de recherche abouti en ce qu'elle propose avant tout une réflexion méthodologique sur l'utilisation du numérique en dialectologie perceptuelle. Cette réflexion nous amène à nous poser d'autres questions en perspective de recherches futures:

- une enquête perceptuelle numérique peut-elle être une finalité en soi ou bien doit-elle être pensée et inscrite, comme c'est notre cas, au sein d'une étude sociolinguistique et/ou phonologique (ou autre)?

- comment rendre accessible une enquête perceptuelle numérique aux personnes âgées et aux personnes en situation d'illettrisme?

- Enfin, et c'est tout l'enjeu de la réflexion initiée par cette étude, les données perceptuelles numériques ont-elles une valeur scientifique équivalente aux données de terrain?

\section{BIBLIOGRAPHIE}

AMADOR-Moreno Carolina, 2010, An Introduction to Irish English, Londres, Equinox Publishing Ltd.

BOUNDS Paulina, 2010, « Perception of Polish Speech Varieties », Poznań Studies dans Contemporary

Linguistics, $\mathrm{n}^{\circ} 46$, p. 155-176.

BRULARD Inès \& NAVARRO Sylvain, 2015, La prononciation de l'anglais contemporain dans le monde: variation et structure, Toulouse, Presses universitaires du Mirail. 
CHAMBERS Jack \& TRUdGill Peter, 1998, Dialectology, Cambridge, Cambridge University Press.

CHATELlier Hugo \& Viollain Cécile, 2018, « De petits corpus pour une grande base de données sur l'anglais oral contemporain : quels enjeux à la lumière du programme PAC ? », Corpus, nº 18.

CRAMER Jennifer, 2016, « Perceptual Dialectology », Oxford Handbooks Online, p. 1-29.

DALBERA Jean-Philippe, 2013, « La trajectoire de la dialectologie au sein des sciences du langage. De la reconstruction des systèmes dialectaux à la sémantique lexicale et à l'étymologie ", Corpus, $\mathrm{n}^{\circ} 12$, p. 173-200.

FALKERT Anika, 2012, « La dialectologie perceptuelle : problèmes et perspectives », Dialectologia et Geolinguistica, n 20, p. 108-129.

GaLly Sylvia, 2017, Identités linguistiques perçues : quelques localités des "vallées vaudoises » du Piémont occidental (Italie), thèse de doctorat, Université Grenoble Alpes, Grenoble.

Gilula Zvi, 1986, « Grouping and Association in Contingency Tables: An Exploratory Canonical Correlation Approach », Journal of the American Statistical Association, n 81, p. 773-779.

GRABOWSKI Beatrice, 2016, « P $<0.05$ " Might Not Mean What You Think: American Statistical Association Clarifies P Values ", JNCI Journal of the National Cancer Institute, $n^{\circ} 108$, p. 4-5.

GRIES Stefan Thomas, 2009, « What Is Corpus Linguistics? ", Language and Linguistics Compass, $\mathrm{n}^{\circ} 3$, p. 1225-1241.

GROOTAERS Willem A., 2000, « Origin and Nature of the Subjective Boundaries of Dialects » [1959], The Japanese Journal of Language in Society, vol. 2, $\mathrm{n}^{\circ} 2$, p. 58-77.

Gut Ulrike \& Voormann Holger, 2014, « Corpus Design », dans J. Durand, U. Gut et G. Kristoffersen (éds), The Oxford Handbook of Corpus Phonology, Oxford, Oxford University Press, p. 13-26.

HICKEY Raymond, 2005a, Dublin English: Evolution and Change, Philadelphie, John Benjamins Publishing.

HICKEY Raymond, 2005b, « Development and Diffusion of Irish English », dans R. Hickey (éd.), Legacies of Colonial English, Cambridge, Cambridge University Press, p. 82-118.

HICKEY Raymond, 2013, A Dictionary of Varieties of English, Malden (MA), Wiley Blackwell. JAFARI Mohieddin \& ANSARI-POUR Naser, 2019, « Why, When and How to Adjust Your P Values? », Cell Journal (Yakhteh), $\mathrm{n}^{\circ}$ 20, p. 604-607.

JUNG Inkyung, 2017, « Some Facts That You Might Be Unaware of about the P-Value », Archives of Plastic Surgery, $\mathrm{n}^{\circ}$ 44, p. 93-94.

LAURENCELLE Louis, 2012, « La représentativité d'un échantillon et son test par le Khi-deux », Tutorials in Quantitative Methods for Psychology, $\mathrm{n}^{\circ}$ 8, p. 173-181.

MCENERY Tony, 2012, Corpus Linguistics: Method, Theory and Practice, Cambridge, Cambridge University Press.

NGUYEN Noël, 2007, « La perception de la parole », dans J. Durand, N. Nguyen et S. Wauquier (éds), Phonologie et phonétique, Paris, Hermès Science Publication, p. 425-447.

PAVEAU Marie-Anne, 2007, « Les normes perceptives de la linguistique populaire », Langage et société, $\mathrm{n}^{\circ} 119$, p. 93-109. 
PAVEAU Marie-Anne, 2008, « Le parler des classes dominantes, objet linguistiquement incorrect ? ", Études de linguistique appliquée : revue de didactologie des langues-cultures, $\mathrm{n}^{\circ} 150$, p. $137-156$.

PRESTON Dennis, 1999, Handbook of Perceptual Dialectology, vol. 1, Philadelphie, John Benjamins Publishing Company.

SINCLAIR John, 1991, Corpus, Concordance, Collocation, Oxford, Oxford University Press.

TEUBERT Wolfgang, 2005, « My Version of Corpus Linguistics ", International Journal of Corpus Linguistics, $\mathrm{n}^{\circ} 10$, p. 1-13.

VIROLE Benoît, 2006, «La perception phonétique », dans B. Virole (éd.), Psychologie de la surdité, Louvain-la-Neuve, De Boeck Supérieur, p. 105-137.

WELLS John, 1982, Accents of English, Cambridge, Cambridge University Press.

\section{NOTES}

1. Pour davantage de précisions, voir Cramer (2016).

2. D'après Preston, cette connotation négative vient essentiellement de l'association des dialects aux traditional dialects.

3. Nous remercions vivement Cécile Viollain qui nous a éclairé sur la distinction " perceptive » / « perceptuelle».

4. Nous abordons plus en détail la notion d'« imaginaire perceptuel » en 2.3.

5. Pour une description détaillée des tâches principalement utilisées en dialectologie perceptuelle, voir, entre autres, Preston (1990 : xxxIv-Xxxv) et Gally (2017 : 146-147).

6. Nous n'avons trouvé aucune traduction convaincante pour ces deux termes et préférons donc conserver les termes en anglais.

7. Par « textes ", de l'anglais texts, nous entendons toute production langagière, qu'elle soit sous forme écrite ou orale (Teubert, $2005: 3$ ). Voir également Gries (2009).

8. Les questions $4 \mathrm{a}$ et $4 \mathrm{~b}$ dépendent de la réponse fournie à la question 4 . Ainsi, si la réponse à la question 4 est "oui ", les questions $4 a$ et $4 a$ n'apparaissent pas. À l'inverse, les questions apparaissent si la réponse à la question 4 est «non ».

9. «1. Genre / 2. Âge / 3. Où vivez-vous à Dublin? Indiquez le quartier; ne donnez pas votre adresse. / 4. Avez-vous toujours vécu à Dublin? / 4a. Quand avez-vous déménagé à Dublin ? / $4 \mathrm{~b}$. Où viviez-vous avant de déménager à Dublin ? / 5. Où est née votre mère ? / 6. Où est né votre père ? / 7. Quel est votre profession (le cas échéant) ? / 8. Quel est votre niveau d'études (le cas échéant)?»

10. Voir <www.cso.ie/en/census/census2016reports/interactivemaps/>.

11. Nous reviendrons sur la délimitation en 3.4.

12. Compte tenu du format adopté par cette tâche de "dessin» sur fond de carte revisitée, les espaces ont toute leur importance pour ne pas confondre les districts.

13. «Voici une carte de Dublin sur laquelle figurent les noms des quartiers : en vous aidant de la carte ci-dessous, pouvez-vous faire des regroupements de zones où vous pensez que les locutrices et locuteurs parlent de la même façon? Vous pouvez indiquer autant de groupes que vous le souhaitez.

Pour identifier un groupe, veuillez vous référer à l'exemple suivant :

Groupe A = 124 3a 8 Groupe B = 187205 11a 11b Groupe C = 16 12a 12b 24a Groupe D = DRa DRb $1022 \mathrm{a}$ Groupe $\mathrm{E}=\ldots$ 
Vous pouvez utiliser autant de nombres que vous le souhaitez (nul besoin de vous servir de tous les nombres). Merci d'insérer des espaces entre les nombres. »

14. «Il a demandé à ses enquêtés s'ils percevaient des différences plus ou moins importantes entre leur propre variété et celles parlées autour d'eux [...].

Toutefois, comme j'ai pu l'indiquer auparavant, sa question n'était pas formulée correctement. On ne peut demander à un locuteur lambda de situer les frontières dialectales qui séparent des variétés qui lui sont éloignées géographiquement; il commettrait inévitablement des erreurs. De plus, parce qu'il existe bel et bien des différences autour de soi, il est fort probable que les enquêtés répondent par l'affirmative si on leur demande s'ils perçoivent des différences entre leur variété et les variétés parlées dans le village voisin. C'est la raison pour laquelle, qu'en 1944, j'estimai erronée la formulation de la question posée par Grootaers. On devrait plutôt demander aux enquêtés d'indiquer où sont parlées les variétés semblables. »

15. La méthode consiste à numériser les cartes papier obtenues auprès de locuteurs et colorer les zones repérées dans le logiciel Adobe Photoshop CS2. Ensuite, ces zones sont converties, avec le programme PICtoASCII, en symboles ASCII. Dans le document obtenu figurent des couleurs associées à différents symboles, mais également des espaces blancs qui représentent les zones qui n'ont pas été repérées par les locuteurs. Après passage dans Microsoft Excel, les symboles sont comptabilisés semi-automatiquement dans chaque cellule à l'aide de formules. Cette manipulation permet d'obtenir un tableur de la forme de la zone étudiée (la Pologne dans l'enquête de Bounds) et présente un ensemble de cellules dans lesquelles figure un nombre. Ce nombre désigne le nombre d'occurrences de repérage par les locuteurs. Ces données chiffrées permettent, par la suite, de convertir le tableur en carte sur laquelle figure un gradient qui symbolise la fréquence de repérage de chaque point sur la carte par les locuteurs.

16. Commentaires sur lesquels nous reviendrons en quatrième partie.

17. L'« id » correspond à l'ordre dans lequel les personnes ont répondu au questionnaire.

18. Voir 3.2.2.

19. Version 5.0.6 au moment de l'enquête.

20. Voir 3.4.1.

21. Il importe de noter que les lettres (A, B, C...), combinées au code couleur, ont pour simple but de nous permettre de classer l'ordre dans lequel les groupes de zones ont été repérés par chaque enquêté. Le groupe A correspond au premier groupe repéré et ainsi de suite. Par ailleurs, chaque groupe représente une variété potentielle qui serait différente de celle parlée dans un autre groupe. Ainsi, pour chaque enquêté, dans les zones regroupées dans un groupe A, les locuteurs parleraient une variété différente des locuteurs des zones regroupées dans un groupe $B$, etc.

22. Notons que dans un test du khi-deux d'ajustement $T$ se calcule ainsi : $T$ = effectif observé total $x$ pourcentage population

23. Le degré de liberté $(d d l)$ se calcule ainsi : $d d l=($ nombre de lignes -1$) \times($ nombre de colonnes -

1). Ce calcul est valable si l'on se trouve dans un tableau à distribution croisée. Si les données sont réparties dans un tableau à une dimension, alors le ddl sera calculé ainsi : nombre de lignes (ou colonnes) - 1. Le ddl est défini par Eisenhauer [2008] ainsi : « [...] in the most general terms and on the most elementary level, we may think of degrees of freedom as the number of pieces of information that can be freely varied without violating any given restrictions. "

24. La table de la loi du khi-deux est disponible sur < https://www.google.com/ url[...]archimede.mat.ulaval.ca[...]-1920-Loi-du-khi-deux.pdf>.

25. Le test du khi-deux d'indépendance vérifie l'une des deux hypothèses suivantes :

$\mathrm{H}_{0}=$ il n'y a pas de lien de dépendance entre les deux variables si le khi-deux calculé est inférieur à la valeur critique $\rightarrow \mathrm{H}_{0}$ acceptée si $\chi^{2}$ observé < valeur critique ;

$\mathrm{H}_{1}=$ il y a un lien de dépendance entre les deux variables si le khi-deux calculé est supérieur au khi-deux théorique (déterminé par le seuil de signification) $\rightarrow \mathrm{H}_{1}$ acceptée si $\chi^{2}$ observé > valeur critique. 
26. Pour plus d'informations sur la valeur $p$ et sur les calculs à effectuer, voir Grabowsky (2016), Jafari et Ansari-Pour (2019), Jung (2017).

27. $p=0,74$.

28. $\chi^{2}=18,003(p<0,001)$.

29. Voir 3.3.

30. L'équivalent $\mathrm{du}$ baccalauréat en Irlande est le Leaving Certificate: <http:// www.citizensinformation.ie/en/education/state_examinations/ established_leaving_certificate.html>.

31. Le chiffre « 5 » surmonté d'une flèche en haut de la carte désigne cinq enquêtés dont le lieu de résidence est situé dans la périphérie nord de Dublin et n'est pas représenté sur la carte.

32. $\chi^{2}=6,963(p>0,05)$.

33. $\chi^{2}=11,787(p>0,05)$.

34. Toutes les personnes interrogées vivent à Dublin depuis au moins 2018.

35. $\chi^{2}=49,074(p<0,001)$.

36. $\chi^{2}=18,383(p<0,002)$.

37. $\chi^{2}=48,632(p<0,001)$.

38. Pour plus d'informations sur la prosodie sémantique, voir Sinclair (1991).

39. «[1] Snob et désagréable / [2] Distingué mais d'une manière agaçante / [3] Snob, prétentieux. »

40. Une analyse outillée permettrait d'en apprendre davantage sur les perceptions véhiculées à travers les commentaires métalinguistiques. Toutefois, le cadre contraint du présent article ne nous permet pas de développer ce point qui fera l'objet d'une recherche ultérieure.

\section{RÉSUMÉS}

Dans le cadre d'une étude en perceptual dialectology cet article propose d'étudier l'anglais dublinois contemporain au travers d'un corpus perceptuel numérique construit en 2020 . Une réflexion méthodologique sur la constitution d'un corpus perceptuel au format numérique et sur les enjeux suscités par un tel format est proposée. Suit une réflexion sur le statut épistémologique de la perceptual dialectology et sur le choix de traduction en français du terme perceptual. La première partie s'achève sur une brève discussion autour de la notion de représentativité en linguistique de corpus afin de justifier la taille du corpus constitué. La seconde partie présente, de manière la plus exhaustive possible, la méthodologie adoptée dans la création du corpus et le traitement des données collectées. La troisième partie présente le corpus et quelques exemples de résultats que l'on peut obtenir grâce à un corpus perceptuel numérique.

This article studies contemporary Dublin English, within the theoretical framework of perceptual dialectology, using a digital corpus I created in 2020. I present methodological reflections on the creation of the digital corpus and I discuss the stakes involved in the use of such an unconventional corpus format in perceptual dialectology. The first part of this article addresses the epistemological status of perceptual dialectology and the translation of the term "dialectology" in French. I also discuss the notion of representativity in corpus linguistics to account for the size of my corpus. The second part is dedicated to the methodology used in the creation and processing of the corpus. In the third part, I present the corpus data and some results that can be obtained using a digital perceptual corpus. 
INDEX

Keywords : perceptual dialectology, digital corpus, corpus linguistics, Dublin English, variation, Covid-19

Mots-clés : dialectologie perceptuelle, corpus numérique, linguistique de corpus, anglais dublinois, variation, Covid-19

\section{AUTEUR}

\section{CHRISTOPHE COUPÉ}

Centre d'Études linguistiques - Corpus, Discours et Sociétés (UR CEL),

Université Jean Moulin Lyon 3

christophe.coupe1@univ-lyon3.fr 